دور جماعات وتنظيمات الاسلام السياسي في اذكاء الصراع الطائفي والديني في مصر في عهد الرئيس محمد انور السادات (1970- 1981)

خلات موسى يوسف" و عبدالفتاح علي البوتاني و شيرزاد زكريا محمد

فاكولتي العلوم الإنسانية - جامعة زاخو، اقليم كرستان-عيراق.

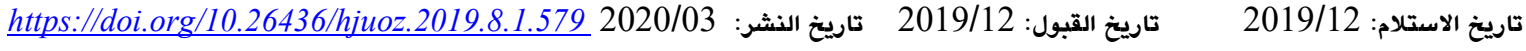

الملخص:

تباينت التفسيرات في تحليل احداث الفتنة الطائفية في تاريخ مصر المعاصر، الا أن السلطة الحاكمة تتحمل قدر كبيرا من المسؤولية

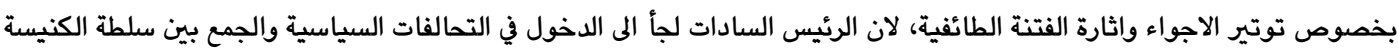

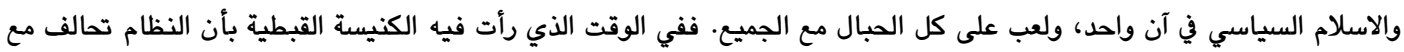
الاسلام السياسي لتحقيق بعض من اهدافه السياسية، مما اثار قلقهم البالغ من استمرار تلك السياسة ومن اثار التمييز ضدها. ومن التان

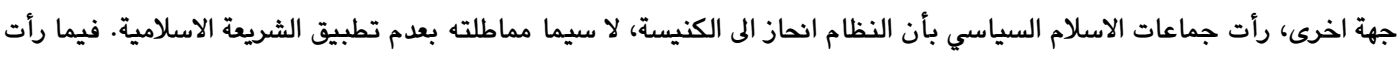
النظام بأن كلا الطرفين الكنيسة والاسلام السياسي عناصر لتهديد الامن وزعزعة الاستقرار السياسي. ولم تتوان السلطة في ممارستها لتلك السياسة باحتواء النزاعات السياسية لكلا الطرفين بمنطق سليم، وايجاد ثقة متبادلة بينهم، مما افقدت صوابها السياسي الى حد كبير، وعجز السلطة في الحفاظ على التوازن بينهما بحنكة وحكمة ومهارة سياسية. وهذا ما جعل كلا الطرفين في النهاية خصمين لدودين للحكومة، فضلا عن الصراع الأيديولوجي بين الطرفين، مما ادى الى تصاعد التوتر ويالتالي الى اندلاع مواجهات عنيفة.

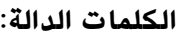

بالدراسة، وضم الكثير من المعلومات الاصيلة حول الموضوع، ومجلة (الدعوة) لسان حال جماعة الاخوان، وكتاب (الاقباط الكنيسة أم الوطن قصة البابا شنودة الثالث) لمؤلفه عبداللطيف المناوي، وكتاب (الفتنة الطائفية في مصر جذورها وأسبابها دراسة تاريخية وئية تحليلية) لمؤلفه جمال بدوي، الا انه كان منحازا، ولم يضم كل الحقائق بل حاول اخفاءها، ودعم طرف جماعات وتنظيمات الاسلام السياسي ضد الاقباط.

\section{2. خلفية تاريخية عن الاقباط في مصر}

شهدت سنوات السبعينيات من القرن العشرين قضية شائكة ومعقدة في مصر، سميت في الساحة السياسية بـ"الفتنة الطائفية"، اذ تعرض واقع المجتمع المصري الى أحداث أقرب الى الشرخ الاجتماعي والطائفي نتيجة العوامل المحلية والدولية عدة، وجعل التطرق اليها من قبل الباحثين

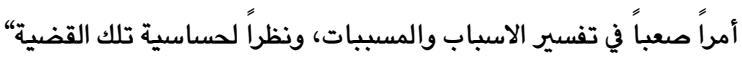
شبه بعضهم الخوض فيه كالخوض في (حقل الالغام)(1)، اذ ساهمت أطراف معنية عدة بشكل أو بآخر في اثارة النعرة الطائفية، نتيجة تراكم

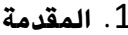

تعد أحداث الفتنة الطائفية بين المسلمين والاقباط من الأحداث ألداخلية البارزة في عهد الرئيس محمد انور السادات (1970- 1981). اذ كان مذا الصراع سببا في احداث شرخ كبير في المجتمع المصري، وتسبب في حدوث خسائر بشرية ومادية تركت آثارا بعيدة المدى على المجتمع المصري.

تعددت الاسباب والعوامل التي أسهمت في ظهور الاحداث في هذه المرحلة، وكان للثالوث (الحكومي- الاسلامي- القبطي) دور كبير في تأجيج هذا الصراع وعدم السيطرة عليه . اذ اتخذت كل الاطراف مواقف متشنجة تجاه الأخر، ولم تكن سياسة الحكومة حكيمة من اجل نزع

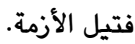
جرى التطرق الى الاسباب التي أدت الى حدوث هذا الصراع، ومن ثم دور

الجماعات والتنظيمات الاسلامية منه، وأبرذ الاحداث التي وقعت. افادت مجموعة من المصادر المتعلقة بالموضوع البحث، لعل أبرزها، كتاب (الاقباط في وطن متغير) لمؤلفه غالي شكري، والذي اختص 
من الاقباط الاخرين، فأصبح عدد مقاعدمم (12) مقعدا، بالاعتماد على النظام السياسي وحقه الدستوري في تعيين عشرة اشخاص، ويرجع هذا الامر الى تصاعد مدّ تيار الاسلام السياسي في مصر، مما أثر على نجاح

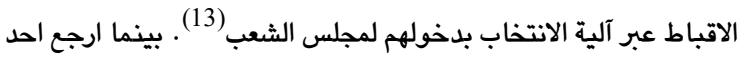
الباحثين غياب الاقباط في المشاركة الفعالة في الحياة السياسية الى عوامل سياسية وتاريخية وكنسية، والتي أدت الى ظهور نمط اطلق عليه (العزوف السياسي) عن المشاركة في الانتخابات العامة أو الاحزاب السياسية والمعارضة، وياستمرار هذه العوامل (الاستبعاد والتهميش السياسي) مما اسفر عن ظهور الاقباط ككتلة على اساس ديني أو

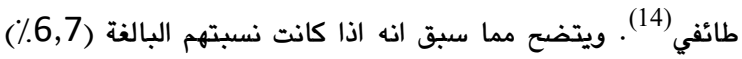
صحيحة، ويمتلكون (12) مقعدا فقط من مجموع (360 ) مقعدا في مجلس الشعب، فأن هذا يعد ذاته غبنا بحق دورهم ومشاركتهم في النظام

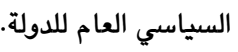

\section{3. اسباب وعوامل الفتنة الطائفية}

لم تكن احداث الفتنة الطائفية حدثا جديدا نسبيا في تاريخ مصر المعاصر، اذ تفاعلت مجموعة من الاسباب أدت في اندلاعها، اذ ظهرت حوادث متفرقة ويشكل اوسع منذ بداية تولى الرئيس محمد انور السادات الحكم الذي واجه الكثير من المشاكل والتحديات الداخلية والاخطار، فقام بإفساح المجال امام جماعات وتنظيمات الاسلام السياسي، وقام برفع شعر (دولة العلم والايمان) و(الرئيس المؤمن) وما نص الدستور على جعل مبادىء الشريعة الاسلامية مصدر رئيسي للتشريع، كما لجأ الى مهادنة التيار الاسلامي وما صاحبه من استخدام التيار الاسلامي

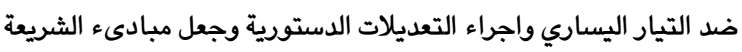
الاسلامية المصدر الرئيسي للتشريع من اجل احتضانهم. فأثارت تلك الخطوات والمؤشرات قلق الاقباط من سياسة الرئيس السادات، والتي تمحورت في التوظيف السياسي للدين الاسلامي ورموزه في العملية السياسية، مما اثار توتر طائفيا والذي ترتب عليه خشية الاقباط من نظام امل الذمة في الفقه الاسلامي التقليدي والذي يعصف بمفهوم المساواة والمواطنة، وبرز كذلك تشدد مضاد من جانب المؤسسة الاسلامية الرسمية (الازهر) يقوده الشيخ عبدالحليم محمود (15) للمطالبة بتطبيق الشريعة الاسلامية(16)، اذ انزعجت الكنيسة القبطية من التوجه الحكومي، بالإضافة الى اضطهادهم في التفرقة الوظيفية، مما

كرس شعورا عميقا لديهم بأنهم مواطنون من الدرجة الثانية(17). من العوامل الاخرى التي أدت الى ظهور الفتنة، كان الجهل وغياب الحس به مرن

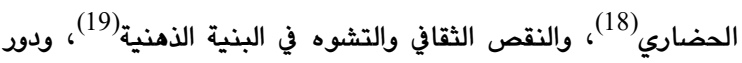
عمل الاسلام السياسي، اذ كانت للحركة الاسلامية تصور لبناء عالم جديد أساسه ان يكون للمسلمين دولة تحكم بالشريعة، ولم يكن في ذهنها كيفية التعامل مع غير المسلمين في تلك الدولة، وان الفقه التقليدي هو المصدر الرئيسي في رؤيتهم لغير المسلمين(20).
كم هائل من الأسباب، والتي ترجع بشكل رئيس الى (مثلث التناقض والخلاف) وهي السلطة الحاكمة والاسلام السياسي والكنيسة.

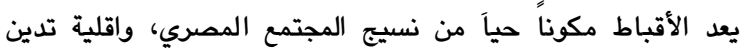
بالمسيحية، ومنا مصطلح الاقلية والاغلبية يشير الى النسبة العددية(2)، لان مصطلح الاقلية يحمل مفهومين الأول يقوم على الاعداد، والثاني يحمل معنى سياسيا. والاقباط يؤكدون على انهم ليسوا بأقلية، ويرفضون وصفهم بالأقلية، ويوافقون على انهم اقلية من حيث العدد بالمقارنة مع المسلمين، لان المصطلح غالبا ما يشير الى الجماعات التي تختلف عن الاغلبية في متغير واحد على الاقل، في حين يختلف اقباط مصر في متغير الدين فقط (3)، ويمعنى آخر ان التعامل مع التبعية الدينية

لتحديد الاقلية أو الاكثرية هو في حد ذاته افتراض ايديولوجي (4). ينتمي معظم الاقباط في مصر الى الكنيسة الارثوذكسية القبطية، ومقرها الاسكندرية، وتتمتع الكنيسة القبطية باستقلال ديني ومؤسسي عن المراكز الكنسية الأخرى في العالم، أي أنها كنيسة وطنية مستقلة (5). كما وتعد مؤسسة الكنيسة من المراكز الدينية المصرية العريقة، وتشغل موقعاً مرموقاً في المؤسسات والكنائس والمذاهب الدينية، وهي أحد محاور تأسيس الهوية المصرية لدى الاقباط الارثوذكس وتاريخها الديني والاجتماعي وتقاليدها (6). يسود نسبة الاقباط، قسط من الغموض، اذ تفاوتت المصادر بتحديد نسبتهم، حيث يؤكد احد الباحثين ان نسبة المسيحيين في مصر بغض النظر عن مذاهبهم هي (10٪) (7). الا أن الاحصاء السكاني الرسمي توني (الجهاز المركزي للتعبئة العامة والاحصاء المصري) الذي اجري في

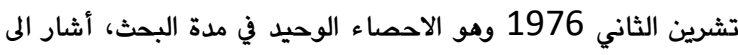

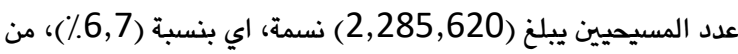
المجموع الكلي لعدد السكان البالغ (37,543,000) وقتذاك(8). وجادل البابا بخصوص النسب الرسمية للأقباط في مصر دون تحديد نسبة معينة، اذ أشار بأن عدد التعداد الموجود لا يناسب الواقع (9). الا انه من الظاهر بأن النسبة الفعلية للأقباط كانت تتناقص بشكل مستمر، وقد تضافرت عدة عوامل في انخفاض نسبتهم، منها تفوق معدل مواليد المسلمين، والتحولات الدينية في الاسلام، أي تحولهم من المسيحية الى الاسلام، وعامل الهجرة الى الخارج، وغياب تعدد الزوجات وصعوبة الطلاق، ويالمقابل انتشار تحديد النسل، ووجود نظام الرهبنة على نطاق ضئيل (10)، فضلا عن الارتفاع النسبي في مستواهم التعليمي والاقتصادي، مما يجعلهم ينجبون عددا اقل من الابناء (تصديد النسل)(11)، الى جانب مضايقات جماعات وتنظيمات الاسلام السياسي، ومحاولتهم فرض تطبيق الشريعة الاسلامية وخوفهم من

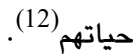
شارك الاقباط في اُولى انتخابات مجلس الشعب في عهد الرئيس محمد انور السادات (1970- 1981) والتي جرت في 26 تشرين الاول 1971 وحصلوا على ثلاث مقاعد من مجموع (360)، الا ان الرئيس عين تسعة 
واحدة اذا طبقت الشريعة الاسلامية مل يعامل المسيحيون كمواطنين لهم كل حقوق المواطنة؟ أم يعاملون كأهل الذمة أو كأهل كتاب أو مستأمن أو ككفار، ولكل كلمة من هذه الكلمات بند طويل عرض في

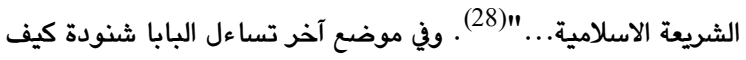
سيكون موقف جماعات وتنظيمات الاسلام السياسي من المسيحيين وطريقة معاملتهم لهم، في الوقت الذي يكفرون مسلمين آخرين في بعض

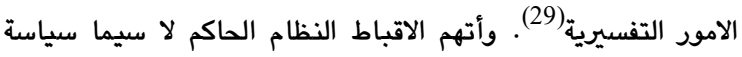
الرئيس السادات في مقامه الاول، وكتب غالي شكري وهو قبطي بهذا الصدد يقول:"...، لم يبدأ التطرف وانعكاسه المباشر على الاقباط الا في عهد السادات، حين خرج المعتقلون بكل ما في صدورهم من غضب، لم يكن تفجيره بوجه الدولة ممكنا فهي التي اخرجتهم، فتحول بعضهم بهذا الغضب نحو المسيحيين الذين لم يسجنومم ولم يعتدوا عليهم قط" (30). لم تتوان الدولة لإيجاد توانن الصحيح في العلاقات بين جماعات وتنظيمات الاسلام السياسي والاقباط، وأعطى أحد الباحثين تفسيرا أقرب الى الواقع، اذ أن الدولة أخطأت في معالجة مشكلة جماعات وتنظيمات الاسلام السياسي، التي تراوحت بين العنف المفرط والتشجيع والتدليل الزائد، وان تراكم تلك الاخطاء أدت الى الفتنة الطائفية، وكان الامتداد الطبيعي هي حركة المطالبة بتطبيق الشريعة الاسلامية(31). وفي الاتجاه المقابل رأى التيار الاسلامي ومنه المتشدد هرد بصورة خاصة، ان الاضرار بالأقباط وسيلة لإبراز ضعف النظام

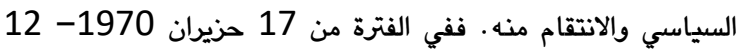
تشرين الثاني 1972 وقعت (11) حادثة طائفية، من بينها الاستيلاء على بعض ثروات الاقباط ومحلات الذهب(32). وأدت تلك الظواهر الى من لئل اشكاليات تمس الوحدة الوطنية، مما تمخضت عن التحام الاقباط على بلى

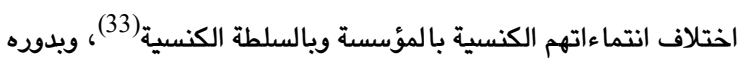
تحولت الكنائس الى نوع من المؤسسات الاجتماعية التي أدت دوراً في التنشئة والتعليم والتعبئة يماثل عملية الاحياء التي شهدتها المساجد الاهلية في السبعينيات، والتي أدت دوراً كبيرا في عمليات التعبئة والتجنيد والتحشيد وصياغة الاتجاهات السياسية الدينية. وساهمت المتغيرات الخارجية كذلك في شحذ الهمم في تغذية عوامل الاستقطاب الداخلي، اذ كان ثمة اهتمام من الغرب ويالذات الولايات المتحدة الامريكية في دعم المؤسسات الدينية في العالم الثالث، لتوظيفها في ادارة الصراع مع الاتداد السوفيتي تحت دعوى ما يسمى بمحارية الالحاد والشيوعية(34).

حدث تحول نوعي في السلطة الكنسية، بعد جلوس البابا شنودة الثالث على كرسي البابوية، نظرا لدورها وعلاقاتها بأتباعها ويالكنائس المسيحية الاخرى، وكان البابا يمتلك مشروعا فكريا واجتماعيا، ودعم هذا المشرع بعض السمات الكاريزمية للبابا وشخصيته الحاسمة وذكائه المتميز(35)، والذي وصفه غالي شكري بـ (الفلاح الفيلسوف)
كذلك أدت الكنيسة دوراً في تأجيج هذه الفتنة، اذ حاولت الكنيسة المصرية الخروج من اختصاصاتها وان تؤدي دوراً سياسيا على غير

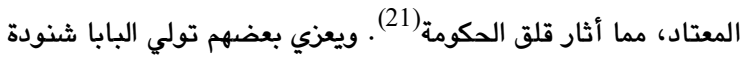
الثالث(22) قيادة الكنيسة البابوية المرقسية القبطية في القامرة في 14 تشرين الثاني 1971(23)، من أخطر المتغيرات على الساحة القبطية، والتي تمثلت في تحويل القيادة الكنسية من الاطار الروحي الخالص والديني البحت، المى قيادة دنيوية ومدنية وسياسية واجتماعية، وغدّت للكنيسة مشروع سياسي للدولة(24)، وظهرت آثار وتداعيات المسألة القبطية على المشهد السياسي المصري بتولي البابا شنودة الثالث، والذي تحول الى زعيم سياسي له مطالب سياسية(25). ارجع عدد من الباحثين الفتنة الى مجموعتين من الاسباب، منها الظاهرة التي انبثقت من تذبذب العلاقات والمعاملات اليومية بين المسلمين والاقباط، بسبب حرص كل جانب على اظهار حماسته الدينية في شكل أنشطة ثقافية أو اجتماعية، تهدف الى تأكيد الذات واثبات وجود كل طرف في مواجهة الآخر، أو في شكل تنافس شديد على بناء المساجد والكنائس في مواقع متقارية. أما النوع الثاني فهي الاسباب الكامنة، وترتبط بالجذور الفكرية التي أستمد كل طرف منها شخصيته، وحدد دوره على مسرح الحياة، ويتمثل في الصراع بين مفهومين متعارضين لمسألة انتماء مصر، مل هي قبطية ام اسلامية؟، ومل تحديد الانتماء لمصر على أساس الجذر التاريخي أم على أساس المعتقد الديني؟. فالفكر القبطي يرى ان دور مصر الحضاري، هو استمرار لوجودما منذ العصر الفرعوني بصرف النظر عن الديانة، والفكر الاسلامي الذي يرى ان مصر تستمد مقوماتها الفكرية والحضارية والوجدانية من

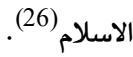

كما علل احد الباحثين بأن مناك ثلاث اتجاهات متناقضة أدت الى الفتنة الطائفية منها، ظهور الجماعات الاسلامية الشاردة التي اوقعت باتِ الخوف في نفوس الاقباط، وخاصة ممارساتها ضد الاقباط، والسياسة التي أنتهجها البابا شنودة وخالف بها الخط المقرد الذي أتبعه آباء الكنيسة، والتي توحي به روح المسيحية انسياقا وراء طموح هو النهضة بالكنيسة واعلاء شأنها، وقاده هو وأستأثر بتمثيل الاقباط في مختلف المجالات، كما حكم الكنيسة بيد حديدية. وأخيرا سياسة السادات التي أتسمت بالتخبط، اذ انه أراد الانفتاح من ناحية، والاستئثار بالسلطة

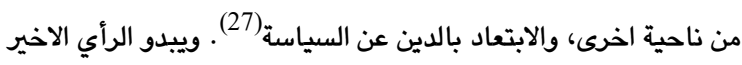
اقرب الى الصحة، لان الاطراف الثلاثة ساهمت في تعقيد الموقف، وتأجيج

خطاب الطائفية والدينية، من اجل تحقيق مصالح سياسية ذاتية. كان للأقباط خوف من الاتجاه السياسي الديني العام للدولة، وأثار تطبيق أحكام الشريعة الاسلامية مخاوفهم، لذا لجأوا الى الكنائس للحفاظ على هويتهم، وفي سؤال وجه للبابا شنودة حول رأيه في تطبيق الشريعة الاسلامية، أجاب:"... أما من جهة المسيحيين، فالمسيحيون وجيه تقف أمامهم مشكلة اساسية يهتمون بها بالدرجة الاولى، وهي عبارة 
أهالي الخانكة بجمع تبرعات لإقامة مسجد بالقرب من بناية الجمعية،

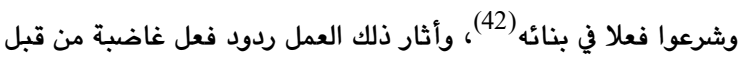
الاقباط بحق مكان العبادة لهم، لعدم اتخاذ الدولة اجراءات كفيلة لإرضاء مشاعرهم، واتهم الاقباط بأن لجماعات الاسلام السياسي، ضلع

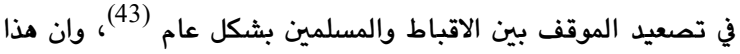
التوتر انعكس بشكل غير مباشر على علاقة الحركة الاسلامية مع الكنيسة(44). ثار الاقباط في وجه المسلمين والحكومة، لعدم اتخاذ الحكومة اجراءات كفيلة باحتواء الموقف، ففي يوم 12 تشرين الثاني 1972 اقبل نحو (400) شخص بالسيارات، وكان اكثر من (100) شخص منهم يرتدون الملابس الكهنوتية، واتجهوا الى مقر الجمعية المحترقة وأقاموا شعائر الصلاة فيها. وفي مساء اليوم نفسه تجمع شباب المسلمين وعدوا تلك الصورة استفزازا لمشاعرهم، فاجتمعوا بمسجد السلطان الاثرف، وخرجوا في مسيرة احتجاج، واثناء ذلك نسب الى أحد الاقباط، انه اطلق أعيرة نارية في الهواء على رؤوس المتظاهرين من مسدس مرخص، وأدى أنى ذلك الى اثارة الجماهير، وتوجهوا الى منزل ذلك الشخص، فأحرقوا منزله ومساكن عدد من المسيحيين، ثم توجه بعض المتظاهرين المى مقر الجمعية واشعلوا النار في احدى حجراتها، ولم تحدث خسائر في الارواح، بينما اصيب ثلاثة اشخاص عرضا بينهم (45). الامر الذي أغضب الرئيس السادات، وأكد بأن البابا شنودة بهذا السلوك لا يتصرف من منطلق حل المشكلات وتهدئتها بل القاء النار

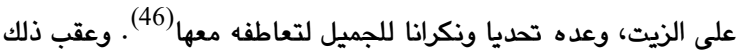
مباشرة اتصل السادات برئيس تحرير جريدة (الاهرام) محمد حسنين هيكل، وطلب منه أعداد خطاب له بأنه سيقوم بتفجير المسالة الطائفية امام مجلس الشعب، وقال له:" انني لا استطيع ان اجلس بقنبلة موقوتة تحت الكرسي...، وان شنودة يريد ان يلوي ذراعي ولن اسمح له أن يفعل ذلك" (47). بدأت وقائع الفتنة الطائفية بشكل فعلي مع بداية حادثة الخانكة، اذ داذ خرجت الكنيسة عن رسالتها الروحية ونهجها التاريخي، فبينما كانت تدعو لدولة علمانية" قدمت نفسها على انها الصوت السياسي الوحيد

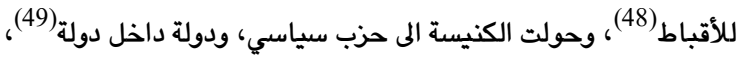
ولهذا اطلق بعضهم "المسيحية السياسية" كتطور ناتج عن مجموعة من المحددات، منها الأزمة القائمة في الهوية والايديولوجية الذاتية وتراجع القومية العربية، وظهور الاسلام السياسي كآيديولوجية سياسية بديلة، رغم انكار البابا شنودة وجود المسيحية السياسية، لعدم وجود نظام سياسي أو دعوة سياسية في المسيحية، بينما في الاصل هي دعوة روحية، وان الاخلاص للحاكم أمر عقيدي بالنسبة لهم، وان معارضة الحكم مرفوضة (50).
لأنه جمع بين سمات الفلاح المصري وينيان الفيلسوف(36)، فيما وصفه وزير الداخلية النبوي اسماعيل بـ(الرجل الوطني)(37). اي انه حصل تغيير مزدوج في الدولة والكنيسة، ويدأت معايير القوى في المجتمع تتغير، وحمل البابا شنودة رؤية محددة بمواجهة مشكلات الطائفة القبطية، تملك مقومات جديدة للقوة الذي يتميز بمستواه العلمي العالي وطموحاته الواسعة، ويدأت له امتدادات في بلاد المهجر خاصة في الولايات المتحدة وكندا، مما أعطاه دعما سياسيا ومعنويا وماديا، وفتح قنوات اتصال مع المؤسسات الكنسية العالمية. ولعدم وجود زعامات مدنية سياسية قبطية منافسة للكنيسة في تأثيرها على الاقباط،

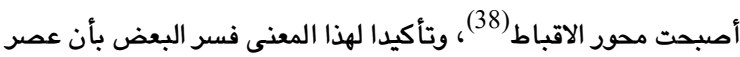
السادات هو عصر النجوم، فبجوار نجومية السادات تألق نجومية البابا شنودة الثالث والشيخ عبدالحليم محمود شيخ الازهر ومتولي الشعراوي كنجوم دينيين شعبيين(39)

\section{4. حادثة الخانكة وتأجيج العنف الطائفي}

بدت الظروف تنذر بالخطر الذي بدأ يهدد الوحدة الوطنية، فجاء رد الفعل على المستوى الرسمي سريعا في شكل الدعوة الى عقد المؤتمر القومي العام للاتحاد الاشتراكي في 14 تموز 1972 لبحث موضوع (الوحدة الوطنية)، ثم دعا مجلس الشعب لعقد دورة طارئة، وانعقدت في اب 1972، وفي تلك الاثناء وقع اعتداء على مبنى جمعية النهضة

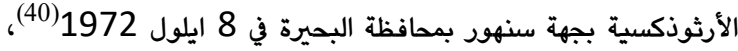
ويغية قطع الطريق عن وقوع أحداث طائفية، اقرت الحكومة قانون رقم (34) لسنة 1972 بشأن (حماية الوحدة الوطنية) واصدر في 13 ايلول 1972 والذي يتكون من (10) مواد، ونص ان حرية العقيدة وحرية الرأي مضمونة بما لا يمس حريات الآخرين أو المقومات الاساسية للمجتمع، وذكر بشكل صريح (الفتنة) ومما جاء فيه: يعاقب بالحبس

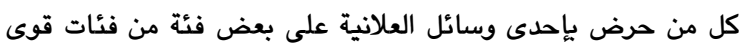
التحالف أو طائفة من الناس أو على الازدراء بها أو اثارة الفتنة بينها،

اذا كان من شأن هذا التحريض الاضرار بالوحدة الوطنية(41). يبدو ان تلك الاجراءات لم تفلح في ايقاف التوتر، اذ بلغ العنف الطائفي بين المسيحيين الاقباط والمسلمين الى درجة بمهاجمة كل طرف للآخر والخرجج من نمط الاحداث الفردية الى الجماعية، ومهاجمة المراكز الدينية منها حادثة الخانكة، وطبقا لتقرير لجنة تقصي الحقائق مجلس الشعب المصري التي تشكلت بعد الحادث، فأن مجهولين اوقدوا النار في 6 تشرين الثاني 1972 الذي كان يصادف عيد الاضحى في دار جمعية اصدقاء الكتاب المقدس، وهي جمعية دينية مرخصة ومسجلة بوزارة الشؤون الاجتماعية، والذي بناه الاقباط بمركز الخانكة (احدى ضواحي القاهرة- شمال القاهرة)، ولم يكن مرخصا له ككنيسة لإقامة الشعائر الدينية. ولكن في واقع الامر كانت تقام فيه الشعائر الدينية، دون اعتراض من الجهات الادارية. ومن جهة اخرى قام بعض المسلمين من 
الديانة المسيحية. الامر كذلك بالنسبة للكتب الدينية التي كتبها مؤلفون من الاقباط" فقد تتعرض لأحكام الاسلام، وفي كلا الحالتين هناك مساس بالعقيدة الاخرى، وطالبت اللجنة بتفعيل قانون المطبوعات والرقابة على النشر، وأخذ التصريح لبعضه من مجمع البحوث الاسلامية أو أمانة الدعوة والفكر بالاتحاد الاشتراكي، وأوصت وزارة الثقافة والاعلام بوضع من مد نظام محكم ومستنير لرقابة الكتب الدينية(54). وفقا لتقرير اللجنة البرلمانية والذي كتب بحذر شديد، ويدرجة كبيرة من الدراية والتوانن، بحيث تمكنت من تشخيص مجموعة من الاسباب الكامنة والتي تسببت في تصاعد اعمال العنف الطائفي بين المسلمين والاقباط، ثم وضعت حلولا ومقترحات مناسبة بعيدة المدى أمام الدولة لقطع دابر الفتنة بين الطرفين، منها اثارة تيار الاسلام السياسي ضد الاقباط، أو اثارة الاقباط على تيار الاسلام السياسي الرسمي وغير الرسمي والمسلمين عموما، ولم تأخذ الحكومة بالتقرير والمقترحات

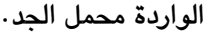
لجأت الحكومة الى تدبير عدد من الحلول والخطط الآنية المؤقتة بدلا من تنفيذ ما جاء في تقرير اللجنة البرلمانية وما توصلت اليه من نتائج ومقترحات، اذ زار الرئيس السادات جامع الازهر، كما زار المقر البابوي في 23 كانون الاول 1972 وعقد اجتماعا مع البابا شنودة الثالث، وأعلن في زيارته عن منح (50) تصريحا ببناء كنائس جديدة، بعد ان طلب البابا شنودة (30- 35) كنيسة، فضلا عن موافقته عن اعادة بناء الكنائس القديمة وترميمها، واصبح الاجتماع ختاما لنزاع مؤقت لفتيل الصدام بين الكنيسة والدولة(55). في الواقع، فان حادثة الخانكة التي وقعت في 6 تشرين الثاني 1972 مثلت نقطة البداية الفعلية في تأزم العلاقة بين المسلمين والمسيحيين من جهة، والسلطة والكنيسة من جهة أخرى، وان حلول النظام لم تكن جذرية في نزع فتيل الفتنة، بل أعقب ذلك توتر في العلاقة بينهما، واستمر شعور الاقباط بالاضطهاد والاقصاء من قبل النظام السياسي.

\section{6. العلاقة بين المسلمين والاقباط اثر حادثة الخانكة}

اتسمت العلاقة بين الكنيسة والدولة بالحذر وعدم الاطمئنان طوال عهد الرئيس السادات، اذ بدأت ملامح توتر تلك العلاقة في الافق، ففي الانتخابات التي جرت سنة 1976 لم يوفق اي قبطي في النجاح في الترشيح للانتخابات، ويلغ عدد الاقباط المعينين ثمانية اقباط من اجمالي عدد النواب البالغ (360) نائبا(56)، اي بنسبة (2,22.)، وفي ولئ نفس الوقت عدت الكنيسة نفسها الممثل الحقيقي للأقباط، ووصلت قوتها ومداها، الى مرحلة وضع المستقل عن سلطة الدولة، وفي ظل تصاعد ظاهرة الاسلام السياسي والدعوة الى تطبيق الشريعة الاسلامية، تصور العديد من الاقباط ان التطورات تدعومم الى اتخاذ موقف جديد تجاه الاسلام السياسي والدولة، لا سيما بعد ان شعرت الكنيسة بقوتها، فدعت الى عقد مؤتمر في الاسكندرية في 17 كانون الثاني 1977 وصدر
5. محاولات السلطة لاستتباب الامن

على اثر حادثة الخانكة ويناء على رغبة الرئيس السادات، اصبح الكاتب والصحفي موسى صبري حلقة اتصال غير رسمية بينه وبين البابا شنودة، وفي خلال لقائهما" طالب البابا بأحقية الاقباط في الوظائف العامة، وفي مجالس شركات القطاع العام وفي وذارة الخارجية وفي المناصب القضائية، وطالب بتعديل النص الدستوري الخاص بتعيين عشرة نواب في مجلس الشعب، وزيادة هذا العدد الى عشرين نائبا، فرفض الرئيس السادات الامر، مبررا ذلك اضاعة الشكل الديمقراطي (51). ويناء على طلب رئيس الجمهورية" تشكلت لجنة برلمانية بمجلس الشعب في 13 تشرين الثاني 1972 لتقصي الحقائق ولبحث اسباب الحادث، وقد توصلت اللجنة الى عدد من الاسباب وحصرتها بثلاثة مقترنة بمقترحات

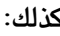

1-الترخيص بإقامة الكنائس، اذ ان تنظيم اقامة الكنائس أو تعميرها أو ترميمها خاضع لأحكام الخط الهمايوني الصادر من الباب العالي في شباط 1856، وكان هذا القانون العثماني هو الوحيد الباقي في الدولة، وتضمن الاقرار بإباحة اقامة الكنائس أو ترميمها ويجب ان يكون مرخصا من الباب العالي، ويناء على ذلك النص اصدرت وذارة الداخلية سنة 1934 عشرة شروط للتصريح ببناء الكنائس، وكانت هذه الشروط لا تزال تطبق الى ذلك الحين، وان بناءها كان يقتضي الحصول على امر جمهوري، علما فأنه ويموجب بيانات الجهاز المركزي للتعبئة العامة والاحصاء فأنه كانت توجد (1442) كنيسة، وأقترحت اللجنة

بإعادة النظر في نظام التراخيص (52).

2-الدعوة والتبشير، بموجب البيانات التي حصلت عليها اللجنة، فان عدد المساجد التي كانت تتبع وزارة الاوقاف لا يتجاوز (4000)

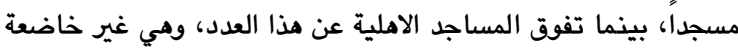
لإثراف وذارة الاوقاف، وطالبت اللجنة اخضاع هذه المساجد لإثراف وزارة الاوقاف، واقترحت ان يكون تعيين ائمتهم بموافقة وزارة الاوقاف. والحال بالنسبة للكنائس كذلك، اذ طالبت اللجنة ان تكون مواعظهم في الدعوة الى الحق والخير والفضيلة، وتعيين راعي الكنيسة بقرار من المطران المختص أو البطريركية. واستطردت اللجنة بموجب المعلومات التي حصلت من وزارة الشؤون الاجتماعية ان عدد الجمعيات الاسلامية المقامة في مصر بلغ (679) جمعية، بينما بلغ عدد الجمعيات المسيحية الارثوذكسية (438) جمعية تتلقى اعانات دورية سنوية من وزارة الشؤون الاجتماعية، وان لتلك الجمعيات دور على الاساءة للأديان الاخرى، بينما لاحظت اللجنة انه بعد ان أصبحت التربية الدينية مادة أساسية في منهاج التعليم، أصبحت من مؤسسات الدعوة، ودعا الى اتاحة

الفرصة لدروس دينية منظمة لتلاميذ الاقباط(53). 3-الرقابة على نشر الكتب الدينية: أوضحت اللجنة ان بعض الكتب الدينية التي تنشر في مصر لمؤلفين مسلمين، كثيرا ما تتعرض لأحكام 
ازدادت حدة التوتر بين الحكومة والكنيسة يوما بعد يوم، اذ تعد سنة 1978 الفاصلة المهمة في تلك العلاقات، فقد بدأ القلق يساور الاقباط في نهج الرئيس السادات، وتصاعدت حوادث الاعتداء في الجامعات المصرية ضد الاقباط من قبل الجماعات الاسلامية المختلفة، واتهم السادات بأنه متهاون معهم(64)، ويالمقابل حاول السادات تحسين العلاقة مع البابا شنودة، فمنح الميدالية الذهبية (جائزة السلام) لسنة 1978 التي حصل عليها من مجلس الكنائس الميثودي العالمي بالولايات المتحدة للبابا شنودة(65)، لكن العلاقات بينهما تفاقمت مرة اخرى، عندما طلب السادات من البابا شنودة تشجيع الاقباط للسفر الى لى له بيت المقدس، لان طريق الحج الى الاماكن المقدسة اصبح مفتوحا، لكن البابا رفض طلبه مبررا ذلك لعدة اسباب منها، ان الوقت غير مناسب ذلك، وانه لا يريد ان يدخل اقباط مصر في خانة التخوين امام الدول

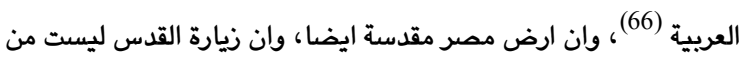
اركان الدين المسيحي، والكنيسة القبطية في مصر هي ام الرهبنة في

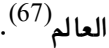
وظلت الحكومة في سياستها الداخلية على احتضان الاقباط، وعندما جرت انتخابات 1979 والتي تمت في مناخ سياسي متوتر وصدام مع المعارضة بكل فصائلها، أظهرت نتائجها بنجاح أربعة مرشحين اقباط في مقابل (10) معينين من قبل الحكومة، ويلغ عدد مقاعد الاقباط المنتخبين والمعينين (14) قبطيا من اجمالي عدد النواب البالغ (360) نائبا، مما يلاحظ ارتفاع مشاركة المنتخبين الاقباط والمعينين عن سابقاتها(68)، ويتضح من الفقرة اعلاه ان ارتفاع مشاركة الاقباط في انتخابات 1979 والحصول على (14) مقعدا نيابيا اي بنسبة (3,89/)، هي اكبر نسبة تمكن الاقباط من تحقيقها في حقبة السبعينيات، والامر يعود الى تحولات عدة في فضاء العمل السياسي والاجتماعي الى عمل ديني، واحتدام المنافسة السياسية بين المسلمين بشكل عام ومنها تيارات الاسلام السياسي وغير مسلمين، وعد الأقباط أنفسهم طائفة دينية مستقلة، ودود الكنيسة في تشجيع الاقباط للمشاركة الفعالة في تلك الانتخابات، ومطالبتها المستمرة في تمثيل الاقباط في الهيئات النيابية تمثيلا حقيقيا لا رمزيا. في واقع الامر، كانت الخلافات بين الحكومة والكنيسة اكبر من مجرد رفع عدد مقاعد الاقباط في مجلس الشعب، لذلك سرعان ما تصاعدت الخلافات بين الكنيسة والدولة مرة اخرى، اذ وصلت الامور الى ذرتها بوقوع عدة أحداث طائفية في سنة 1981، وأسفرت عن وقوع الحرائق في بعض الكنائس، وكان نتيجة هذا التصعيد الطائفي، قيام الكنيسة بأكبر مواجهاتها ضد الحكومة، وكان ذلك في عيد القيامة، اذ قرد المجمع المقدس للكنيسة الغاء الاحتفالات بالعيد، والقى البابا خطابا في 26 اذار 1980 عارض فيها بشدة فكرة ان تكون الشريعة الاسلامية اساسا للقوانين وتطبيقها على غيى المسلمين، وأبدى مخاوفه في حل الدين محل الوطنية، واعلن عدم اقامة صلوات عيد القيامة لهذه السنة، وعوضا عن
عنه بيان منع نشره وقتها، وطرح في المؤتمر مجموعة من المسائل منها: حرية العقيدة، حرية ممارسة الشعائر الدينية، حماية الاسرة والزواج المسيحي، المساواة وتكافؤ الفرص، تمثيل المسيحيين في الهيئات النيابية والتحذير من الاتجاهات الدينية المتطرفة. ثم طالب البيان من السلطات المصرية: الغاء مشروع قانون الردة، والعدول عن التفكير في تطبيق قوانين مستمدة من الشريعة الاسلامية على غير مسلمين، الغاء القوانين العثمانية التي تقيد حق بناء الكنائس، واستبعاد الطائفية في تولي وظائف الدولة على كل المستويات وحرية نشر الفكر والتراث القبطي. واوصى البيان كنوع من الاحتجاج بأن تكون الفترة من 31 كانون الثاني- 2 شباط 1977 فترة صيام- كأحد أساليب التعبير عن معارضتها- وعد المؤتمر في حالة انعقاد مستمر لمتابعة ما يتم في مجال تنفيذ فقراته وتوصياته (57). حالت احداث 18 و19 كانون الثاني 1977(58) دون الشروع في تنفيذ توصيات المؤتمر، فقر الاقباط تأجيل مطالب المؤتمر الى حين اخر،

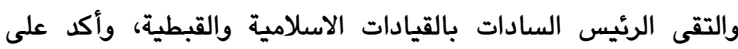

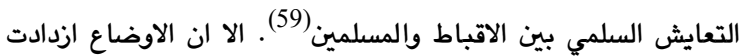

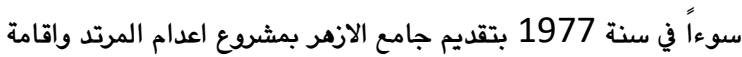
الحدود الى مجلس الشعب لإقراره، وكان لهذا المشروع وقع عميق في نفوس الاقباط، وأحدثت هزة عميقة في اوساطهم، ورأت الكنيسة انها

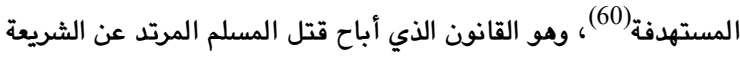
الاسلامية، ويمقتضاه لا يمكن للمسيحي الذي اعتنق الدين الاسلامي

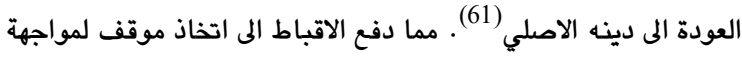
المشروع، فقد عقد المجمع المقدس اجتماعا في الاول من آب 1977 برئاسة البابا شنودة، واصدر قرارا بتقديم مذكرة لرئيس الجمهورية، تضمن رفض الطوائف المسيحية تطبيق الشريعة وقانون الردة، وفي مطلع شهر ايلول 1977 التقي البابا شنودة الثالث بأعضاء مجالس كنائس القاهرة وعدد من المطارنة بمقر الكاتدرائية المرقسية بالعباسية، واتخذ قرارا بإعلان الصوم الانقطاعي ابتداء من يوم 5 ايلول 1977 تعبيرا عن رفض مشروع قانون الردة. كما أدت التكتلات القبطية في

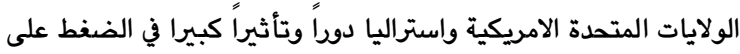
الحكومة من الخارج، وقامت بمظاهرات، فسحبت الحكومة مشروع القانون(62). كما جاءت الانباء من الخارج تفيد ان الاقباط المصريين في الولايات المتحدة يتجمعون للاحتجاج في مظاهرات خلال استقبال الرئيس الامريكي جيمي كارتر (Jimmy Carter) (1977) لوزير الخارجية المصري اسماعيل فهمي، فأرسل الرئيس انور السادات رسالة الى البابا شنودة بالعدول عن تصرفاته، وهدده انه في حال عدم تنفيذه بأنه مستعد بإصدار قرار بإلغاء القرار الجمهوري بتعيينه، فتراجع البابا عن موقفه، وارسل رسالة ود في 10 ايلول 1977 الى الرئيس السادات(63). 
في علاقاته مع خصومه يقوم بفتح الملفات السابقة، ثم يقوم بمهاجمتهم بشدة، وهذا ما حدث مع الاخوان والجماعات الاسلامية كذلك. 8. حادثة الزاوية الحمراء وتداعياتها:

وصلت وتيرة الاحتقان الطائفي الى قمتها في حادثة زاوية الحمراء وذلك في 12 حزيران 1981، اذ تضاريت الروايات حول حقيقة اسبابها، فالرواية الاولى الحكومية ذكرما وزير الداخلية النبوي اسماعيل وأكد ان العملية سبجها تافه، ولكنها اتسعت نتيجة التعبئة والاثارة التي حدثت في منطقة مكتضة بالمسلمين والمسيحيين، والذي حدث هو ان سيدة القت بمياه من شرفتها نزلت على غسيل الساكنة التي تسكن تحتها في البيت، فقامت بينهما مشاجرة، وكانت احداهن مسلمة والثانية مسيحية، وحين عاد نوج الاولى واخو الثانية التي لم تكن متزوجة، وحكت كل منهما فأمسك كل منهما تلابيب الاخرى بعد عتاب، وكان الناس عائدين من الجوامع بعد صلاة المغرب، فتجمعوا وحدثت مشاجرات بين المسلمين والمسيحيين، ووقع نتيجة ذلك عدد من القتلى والجرحى، وتدخلت الشرطة لفضها، دون ضربها بالنار الذين يقومون بالشغب (79). ذكر الوزير النبوي في موضع آخر عندما تقابل في المساء نوج السيدة المسيحية مع شقيق السيدة المسلمة في الطريق دار بينهما عتاب تطور

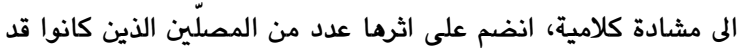
خرجوا لتوهم من الصلاة في المسجد، وكذلك مجموعة من المسيحيين المقيمين بالمنطقة، وأرتفعت الاصوات بأن هناك رجلا مسيحيا حاول الاستيلاء على قطعة ارض بالمنطقة لإقامة كنيسة عليها، فأتجهت مجموعة من المسلمين الى منزل المسيحي الذي افزعه ذلك، فبادر بإطلاق عدة أعيرة نارية اصيب فيها بعض المسلمين، فتوتر الموقف، وأنتشرت شائعات حول مقتل عدد من المسلمين على ايدي المسيحيين، وتحرك المسلمون في مناطق مجاورة من بينهم بعض المتطرفين للأخذ بالثأر (80) اما الاقباط فلهم رواية اخرى على عكس ما ذهبت اليه الحكومة، وذلك بان الفتنة كانت حول قطعة ارض اعلن مسلمون عن حقهم فيها، فاعتزم بعض الأقباط إقامة كنيسة عليها، وتحول من شجار عادي بين الجيران إلى معركة مسلحة، وأصيب سكان الزاوية الحمراء بالتوتر والهلع، ويعد خمسة أيام، ويالتحديد في 17 حزيران 1981 اشتبك المسلمون والمسيحيون في الزاوية مرة اخرى، وكان هناك مجموعة من الصبية تنتقل من حي إلى آخر وصولا الى الزاوية الحمراء بهتافات هي شتائم ودعوات إلى حرق ومدم بيوت ومنازل الأقباط، و يضعون علامات على بعض البيوت لتظهر بأن بداخلها مسيحيون، واشتعلت الفتنة، وتركتهم الشرطة لمدة ثلاثة ايام، قام فيها مثيرو الفتنة والخارجون عن القانون من اللصوص ومحترفي الإجرام، بأعمال السلب والنهب دون أي تدخل لفض تلك المعارك. ويعد ذلك كلف الرئيس انور السادات وزير الداخلية
حضور قداس الجمعة الحزينة، قرر الذهاب الى أحد الاديرة في الصحراء والصلاة من أجل الخلاص مما يعانونه من ضغط، كما اصدر اوامر الى رجال الكنيسة بعدم اقامة المراسيم والاحتفالات والاستقبالات بعيد القيامة لأي مسؤول رسمي للدولة لتهنئة الاقباط كما جرت العادة(69).

\section{7. المواجهة العلنية بين الحكومة والكنيسة}

بدأت المواجهة العلنية بين قيادة الدولة وقيادة الكنيسة، عندما وجه الرئيس انور السادات في خطاب القاه امام مجلس الشعب يوم 14 ايار 1980 اتهاما صريحا للبابا شنودة، بأنه لا يريد الاكتفاء بالرئاسة

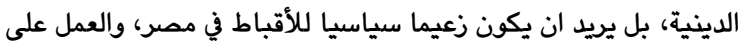

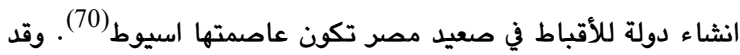
نفي البابا شنودة نفيا قاطعا الاتهام، وأكد بأنه يدخل ضمن باب الدعاية والخرافة واللامعقول، لكونه مشروع غير واقعي بحصر جميع أقباط

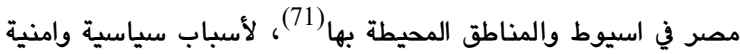
واقتصادية ولاموتية، لأنه ليس من الأمان للأقباط ان يجري عزلهم جميعا في مدينة واحدة قد يسهل الهجوم عليهم، وكذلك ملكية المنازل واراضي والمساجد المملوكة للمسلمين، وكذلك ملكية المسيحيين لممتلكات في انحاء مصر، علاوة ان اللاهوت القبطي يؤكد على فصل الدين عن الدولة(72). ودافع الرئيس السادات في خطابه في الوقت ذاته عن نفسه بالقول انه رئيس مسلم لدولة مسلمة(73)، مما أثار حفيظة الاقباط، وأكد البابا شنودة انهم ليس لديهم بقيام دولة على أساس ديني بناء على قاعدة (دع ما لله الله وما لقيصر لقيصر) (74). كان ذلك الخطاب نقطة تحول في العلاقات بين الكنيسة والدولة، اذ ازدادت توترا في العلاقات بين الحكومة و الكنيسة، الاول يمثله السادات و الثاني يمثله البابا شنودة(75)، وكانت هذه هي المرة الاولى في تاريخ تلك العلاقات بين الجانبين، تلجأ فيها الحكومة الى المواجهة العلنية مع الزعامة الدينية القبطية، وتتهمها بمحاولة جعل الكنيسة سلطة داخل الدولة، ودلالة على ان الأحداث بلفت حدا جعل سلطة الدولة تتخلى عن موقف المراقب، المى موقع المشارك وتشديد قبضتها على مجريات الامور، والتلويح بعصا السلطة ضد التجاوزات التي تصدر عن العناصر المتشددة في الجانبين الاسلامي والمسيحي(76)، مما أثار الخوف في تهدي نفوس المسلمين والاقباط على السواء. فمن ناحية المسلمين، فقد شعروا ان الرئيس تكلم بعصبية شديدة، تنم على ما تحمله من الاقباط ومعاناته معهم، فضلا عن غيظه الشديد منهم ما جعلهم يتعاطفون معه، وشعروا انه يستنجد بهم. ومن ناحية الاقباط فقد أحسوا ان غضب الرئيس من أبيهم الروحي البطريرك قد بلغ حدا مخيفا، وهو ما جعلهم يصابون بالخوف والذعر(77). ولهذا ارجع أحد الباحثين بأن الفتنة

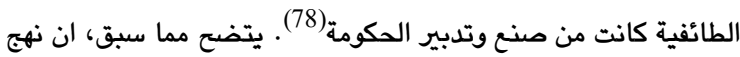
الرئيس السادات السياسي كان أقرب الى المناورة والتآمرية، اذ انه لا يمكن ان يتحدث عن خصومه في عنفوان الاحداث، بل متى ما بدأ التوتر 
التناقضات والخلافات بين الطرفين، الذي حاول كل طرف تحقيق هدف يتقاطع مع هدف الطرف الاخر واثبات أحقية ذلك الهدف، كما ان كلا الطرفين حاولا ندع البغض والكراهية والعداوة في نفوس أتباعهم تجاه الطرف الآخر. على صعيد آلاخر، فان الاوضاع السياسية والاقتصادية والاجتماعية هي التي أثرت على العلاقات بين الاقباط والمسلمين، وان الاسباب غير المباشرة لهذا الاصطدام كانت موجودة. ولهذا فان الروايات التي يجري ذكرها لم تكن سوى الحديث عن السبب المباشر في الواقعة. ومما ساعد على وقوع الحادثة هي ضعف السلطات الحكومية وفشلها في ايجاد دولة المواطنة في مصر، الامر الذي دفع كل طرف لاثبات نفسه

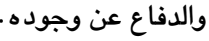
اختلفت المصادر في تحديد عدد القتلى والجرحى في الحادثة، اذ ذكر الرئيس السادات في احد خطاباته ان عدد القتلى (17) قتيلا، منهم (7) من المسلمين و(9) من المسيحيين، وقتيل مجهول الشخصية، و(112) جريحا (86). فيما ذكرت جماعة الاخوان بأن عدد المصابين من المسلمين بلغ (96) شخصا من بينهم عشرة قتلى، ولم تتطرق

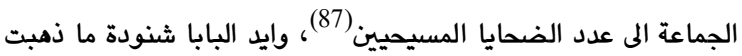
اليه الرواية الحكومية. ويغية الوصول الى حقيقة الحادث، أمر الرئيس السادات بتشكيل لجنة تقصي الحقائق عن احداث الفتنة الطائفية سنة 1981 في مجلس الشعب، وألقت اللجنة بالمسؤولية عن الاحداث على الجماعات الاسلامية وعلى سياسة البابا شنودة الثالث(88). لم تكن حادثتا خانكة والزاوية الحمراء الاولى من نوعها، بل انه في المدة الواقعة بين اوائل السبعينيات الى اوائل الثمانينيات من القرن العشرين، وقعت (48) حادثة عنف طائفي ضد الاقباط في مصر من اجمالي (52) حادثة عنف، واشتملت الاحداث بالهجوم على الكنائس والجمعيات المسيحية وعلى المواطنين المسيحيين وممتلكاتهم، وتركزت اغلبها في قرى ومدن الصعيد وخاصة المنيا وابو قرقاص وينى مزار وقريتي بني

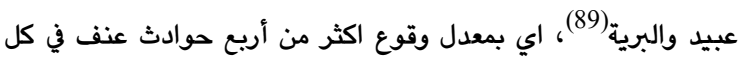
سنة، وأدت تلك الحوادث الى احداث خلل كبير وتوتر العلاقات بين

المسلمين والمسيحيين.

9. تصاعد وتيرة الخلاف بين الحكومة والكنيسة

تصاعدت وتيرة الخلافات بين الحكومة والكنيسة بشكل أشد ووصلت الى حد القطيعة، وكانت زيارة الرئيس السادات الى الولايات المتحدة

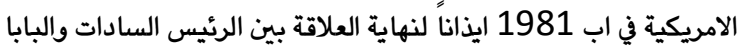
شنودة، وعلى الرغم من ان رئاسة الكنيسة القبطية حثت أقباط المهجر في الولايات المتحدة على الترحيب بالرئيس السادات أثناء زيارته، وعدم اثارة الموضوعات الداخلية، من اجل تجنب استفزازه. الا ان الجمعيات القبطية مناك نشرت اعلانا في بعض الصحف، منها واشنطن بوست(The Washington Post) ونيويورك تايمز The تعبر فيهما عن المضايقات التي يلقاها New York Times)
النبوي إسماعيل بمعالجة الموقف بطريقة سياسية وليس بطريقة بوليسية(81). كذلك روايات اخرى اوردما باحثون آخرون اعطت صورة اخرى، فالرواية الاولى دافعت عن الأقباط، وتتلخص بنزاع بين مسلم وقبطي حول ملكية قطعة ارض، مجاور لمصنع، حصل القبطي على حكم بملكيتها وحيازتها، بعد ان حصل القبطي على الحكم، فقام المصنع بمساعدة أحد الاحزاب باستصدار قرار بتحويل قطعة الارض الى مسجد، وحاولوا اقامة الصلاة فيها، ولكن القبطي منعهم، وأشاع المسلمون انها بهاب تحول الى كنيسة، عند هذا توافد أعضاء الجماعات الاسلامية واستولوا على قطعة الارض، وحاول القبطي الدفاع عنها، حدث صدام بين

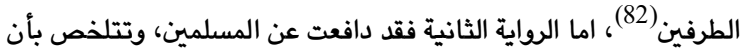
النزاع حدث حول قطعة الارض جعلها المسلمون مكانا للصلاة، وتطور الى معركة استخدمت فيها الاسلحة النارية(83). اما رواية جماعة الاخوان فتقول: بأن المسيحيين هم من بادروا بالاعتداء على المسلمين، وان الاحداث بدأت في يوم الاريعاء في 17 حزيران 1981 عقب صلاة المغرب أمام مسجد النصر بالزاوية الحمراء، اذ كان المسلمون يصلون، وفوجئوا بأن كرة للقدم اصابت المصلين داخل المسجد، والتي كان بعض الشباب المسيحيين يلعبون بها، وعندما خرج

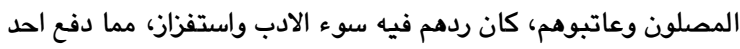
المصلين الى تدذير اخوانه من الاستدراج وطلب منهم الانصراف، فسارع أحد الاشخاص وقبل انصراف المسلمين الى اطلاق وابل من الرصاص في العمارة المقابلة للمسجد، فقتل احد المصلين. فأخذ بعض المسلمين ردود فعل ضد المسيحيين. وعقب صلاة العشاء، وعند خروج المصلين من مسجد النذير الذي يبعد (500) متر تقريبا من مسجد النصر، اطلق "نصراني" واسمه كامل الموان واولاده الرصاص على المسلمين داخل وخارج المسجد، واستمروا في اطلاق الرصاص حتى الساعة الثانية صباح يوم الخميس 18 حزيران 1981، ولم يتوقف اطلاق النار الا بعد القبض عليهم، كما اطلق "نصارى" الرصاص على المسلمين في منطقة الجنينة وعزبة ابو ليلة(84). وأكد الاخوان في خبر نشر في مجلة (الدعوة) في شهر آب 1981، وذكرت :"...المسجد اقيم على قطعة ارض التي حاول بعض غير المسلمين اغتصابها مما كان سببا في انفجار الاحداث الطائفية الاخيرة، وقد اعترفت السلطات المسئولة بأحقية المسلمين في تملك قطعة الارض هذه... وقد أعلن الازهر تبرعه بمبلغ خمسين الف دولار لبناء المسجد الذي سيضم معهدا دينيا ودارا للمناسبات" (85). يبدو ان الاخوان أوددوا روايتين في مدة قصيرة، الاولى حول اعتداء المسيحيين على بعض المصلين المسلمين، والثانية حول قطعة الارض لبناء المسجد، وتبدو الرواية الأخيرة أقرب من الصواب، وان كلا

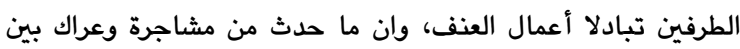
بعض المسلمين ويعض المسيحيين كان نتيجة حتمية ناجمة عن حجم 
الشؤون غير المسيحية بالفاتيكان في شهر نيسان 1978، التقى الوفد بكل من وزير الاوقاف وثيخ الازمر، اشمئزت جماعة الاخوان من تلك

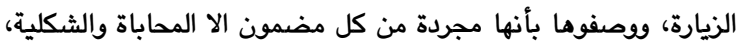
لتجاهل تلك اللقاءات الاشارة الى مواضيع مهمة مثل موجات التبشير ضد الاسلام في كل مكان، والوسائل الخفية التي تستخدمها، والخطط التي تم وضعها لتنصير الشعوب بأسرها في المدى القريب أو البعيد، فضلا عن قضايا تهم المسلمين في العالم مثل تعرض مسلموا الفلبين

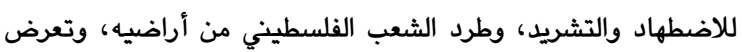
ثعب الصومال المسلم لضربات اثيويية(96). نددت احد المقالات المنشورة في مجلة (الدعوة) بالكنيسة، لانها ماضية ومتشبثة بالحرب الدائمة ضد الاسلام سواء في مجال الفكر أو الحركة، وانها وضعت ايديها في ايدي الاستعمار الحديث، وتصورت انها الستار الواقي والجدار القوي الذي وقف ضد الزحف الاسلامي. كما ان القرائن لحسب رأي المقال تدل ان الكنيسة وضعت يدها في يد الشيوعية التي

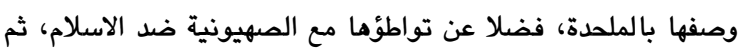
تطورت الامور على اعتبار ان الاسلام من وجهة نظر الكنيسة هو (الخطر الاكبر)، اذ انها اعلنت حربا عالمية شاملة ضد الاسلام راغبة في التخلص منه الى الابد. كما لجأت الكنيسة في حربها الى الاسلوب السياسي الميكيافلي، باستغلالها الاساليب المشروعة وغير المشروعة ضد الاسلام، وهي مستعدة في التعامل حتى مع الشيطان ضد الاسلام، ثم هدد كاتب المقال المسيحيين ذاكرا:"انني اقول لهم-بأعتباري مسلما بالدرجة الاولى، ومعلم تاريخ بالدرجة الثانية- انكم واهمون كل الوهم فيما تتصورون، ودعوني اقول لكم، ان المعركة بين الاسلام ويينكم اذا شئتم بقاء اشتعالها فستمتد وستطول، وانه كجزء من ديننا يتحتم علينا ان نؤمن به ان الاسلام سيظهر على الدين كله، ولو كره المشركون". وشكك كاتب المقال في امكانية تغير نظرة العالم المسيحي واستراتيجيته ومخططاته المعروفة، ودعا العالم المسيحي الى اجراء الحوار بينهما شريطة توقف "النصرانية" غاراتها الكونية على العالم الاسلامي، ووقف حملات التبشير (97) . بلا شك فأن مثل هذه المقالات كانت تؤجج نار الصقد والكراهية بين المسلمين والمسيحيين. علي أية حال، هيأت جماعات وتنظيمات الاسلام السياسي البيئة المؤاتية تماما للفتنة الطائفية، ومنها جماعة الاخوان المسلمين، رغم انها لم تذكر مشاركتها في الاحداث، وانكارما لاي دور فيها (98)، الا انه ومن خلال ادبياتها يتبين عكس ذلك، فالجماعة شاركت ومن خلال اعلامها في حملة الاثارة الطائفية، وكان موقفها من الاحداث هو تعليق

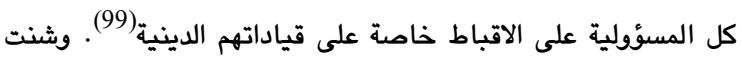
صحافة الاخوان مجوما لاذعا على الاديان السماوية الاخرى ومنها المسيحية، وظهر ذلك بشكل ملموس منذ اوائل سنة 1980، اذ عارضوا فكرة مجمع الاديان الذي كانت مصر تنوي عقدها سنة 1980، وعللوا ذلك بمجموعة من الاسباب، اهمها ان السماحة تجاه
الاقباط في مصر، فضلا عن نشر منشورات تندد بمعاملة الاقباط في مصر معاملة سيئة، ثم قامت تلك الجمعيات بمظامرات ضده في واشنطن، وأمام مكان اقامته، مما أثار استياء السادات من تصرف الكنيسة. وانعكست تلك العلاقة المتأزمة على الوضع الميداني، اذ أسفر عن انفجار قنبلة في 4 اب 1981 بكنيسة (مسرة) بشبرا عن مقتل ثلاثة مواطنين واصابة (59) اخرين، وتم ذلك اثناء زيارة الرئيس السادات للولايات المتحدة، مما يدل على ان الجانبين المتشددين القبطي

والاسلامي كانا قد اعتزما احراج الحكومة كل بوسائله الخاصة(90). فجر الرئيس انور السادات بعد رجوعه من الخارج الصراع مع الكنيسة واخرجه الى العلن، لا سيما بعد تنامي الدور السياسي للبابا شنودة وتوجهه القبطي الصارم، مما دفع الاقباط لان يلتفون حوله كزعيم سياسي لهم، الأمر الذي أثار قلق الرئيس السادات وحكومته بشأن التطور السياسي لدود البابا شنودة وللكنيسة القبطية(91)، فتم اتخاذ سلسلة من الاجراءات لم يستثنى منها الاقباط ايضا، اذ اصدر الرئيس السادات في 2 ايلول 1981 قرارا بإلغاء قرار الجمهورية رقم (2782) لسنة 1971 بشأن تعيين الانبا شنودة بابا للإسكندرية ويطرياركا للكرازة المرقسية، وقرر تشكيل لجنة من خمسة اعضاء للقيام بالمهام البابوية من الاساقفة(92)، وجرى ابعاد البابا شنودة الثالث الى وادي منيكي النطرون، واحتجازه وسط حراسة مشددة في دير الانبا بشوي، واعتقال العديد من الاساقفة والمطارنة والكهنة ضمن حملة سبتمبر (ايلول) (93) 1981

اثارت جماعة الاخوان المسلمين موضوع وضع غير المسلمين مرارا وتكرارا في ادبياتها، اذ ورد في افتتاحية مجلة (الدعوة) في اوائل سنة 1977 موقفهم، على ان هناك صور متعددة نظم فيها موقف المسلم من غير مسلم، فهو اما ذمي واما معاهد واما مستأمن واما محارب. وذكرت بأن المسلم لا يعرف ان الدين الله والوطن للجميع، ولكنه يعرف ان كل شيء في هذا الوجود الله، فمن اراد ان يصرفه عن هذا المعنى

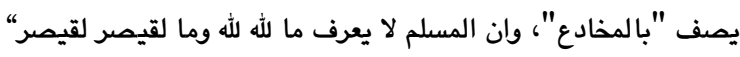
لأنه يؤمن كل الايمان بأن قيصر لا شيء له مع الله والا كان شريكا له في ملكه، والمسلم ينكر الشرك بكل صوره(94). وشن أحد مفكري الاخوان هجوما عنيفا على العلمانية والمسيحية معا، وعد العلمانية بانها تعني اللادينية ووصفها باللفظ الخبيث، كما ماجموا سلطة الكنيسة تاريخيا، وان التحريف ادخل الى الديانة المسيحية. وذكروا ان الدين الذي حبس داخل جدران الكنيسة قد جرى فيه تغييرات، حتى صارت الصلاة تؤدي على انغام الموسيقى، ثم تعقبها حفلات الرقص بين الجنسين تحت الاضواء الخافتة الحالمة بين الالحان الدافئة والساخنة، تحت سمع ويصر رجال الدين بل رعايتهم وتوجيههم (95). ظهر التوتر بشكل واضح بين جماعة الاخوان المسلمين والاقباط في النصف الثاني من السبعينيات، عندما زار مصر وفد الفاتيكان برئاسة الكاردينال سيرجيو بنيدولي (Sergio Pignedoli) رئيس امانة 
يستفحل خطرها، ويستشري خطبها؟! أهذا هو الحسم؟! أم أن للحسم مناسبات لا يتحرك الا وفيها وعندها ويسببها؟! لماذا لم يقض عليها وهي ما زالت تحبو، قبل ان يشتد عودها؟ ! وكان ذلك ايسر من العلاج، واصلح للوطن والمواطنين، أهذا هو السهر على مصلحة الوطن؟..."(104). ومهما يكن غايته من هذا الكلام، الا انه يعبر عن اهولن حقيقة الامر في الواقع. وفي عين الوقت، وجه الاخوان في تموز 1981 نداءا حثوا فيه الشعب المصري (المسلمين والمسيحيين) على دقة التقدير للظروف التي تمر لها البلاد، واهاب النداء بالحكومة لاتخاذ اجراءات سريعة لإعادة الامان، وطالب المواطنين بعدم انسياقهم وراء مخططات الاجنبية التي ترمي الى المساس بالأمن الداخلي، الا انهم في نهاية النداء القوا مسؤولية الحوادث

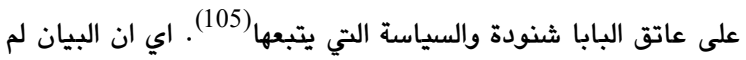
يكن محايدا بل حمل في ثناياه تهما للبابا والمسيحيين. ما تقدم لم تستتب الامور في اعقاب احداث الزاوية الحمراء، اذ ظل الاخوان على موقفهم باثارة الفتنة، اذ نشرت مجلة (الدعوة) مقالا قصيرا بعنوان (الى متى تستمر هذه الاعمال)، وجاء فيه ان بعض المسيحيين يقومون ببعض الامور التي تؤدي الى الفتنة الطائفية ومنها قيام بعض الكنائس بشحن نفوس الاقباط ضد المسلمين، وحث الاقباط على المطالبة بحقوق وهمية بعد افهامهم انهم مضطهدون، وصدور منشورات من عدة جهات مسيحية تهاجم فيها الاسلام والمسلمين، وقيام بعض الاقباط بمحاولة اضفاء الطابع المسيحي على بعض الاحياء وآخرها حي الزيتونة، والدعاية المغرضة ضد الاسلام والمسلمين في مصر، والتي يقوم بها الاقباط المقيمون في الخارج، خاصة في كندا واستراليا والولايات المتحدة الامريكية(106).

مهما كان الامر، عبرت جماعة الاخوان في ادبياتها عن قلقها للدود المتصاعد للأقباط، وتبنت موقفا سلبيا منهم، فقد نشرت لسان حالهم مجلة (الدعوة) في عددما الاخير (64) الذي صدر في مصر في عهد الرئيس السادات مقالا مليئا بالتعصب تجاه الاقباط، ويينت ان الاقباط هم اسعد الاقليات على ظهر الارض، وان كل حقوقهم المادية والادبية ميسرة بل مضاعفة، وأنه يجب عليهم الخضوع التام لنظام الدولة الاسلامية، وهناك واجبات مالية عليهم وهي الجزية والخراج والعشور. أكد المقال بأن كثرة الفتن الطائفية ناجم عن عدم التزامهم في رعاية شعور المسلمين واحترام الدولة، فضلا عن تدليلهم والدعم الخارجي الذي يتلقونه ماديا وادبيا. كما ان من الامور الخطيرة حيازة الكثير منهم الاسلحة، وان كثيرا من الكنائس والاديرة تحولت لمخازن الاسلحة، وكأنها حصون للقتال وليس دور للعبادة، وان البابا شنودة وزعماء الكنائس تحدوا المسلمين، وانه يجب التعامل معهم على قاعدة (لهم ما لنا وعليهم ما علينا). وان هناك "فرية" روجها الاقباط وهي ان الاقباط هم السكان الاصليون

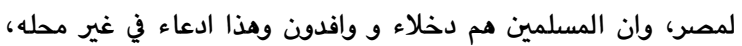
وان الاقباط كانوا متعصبين في التعامل مع المسلمين، وان بعض الاقباط
اهل الكتاب لا تكون بالمظاهر، بل تكون عن طرق الواقع العملي، وهو التمسك بالإسلام نظاما شاملا للحياة، وليس طريق اقامة مجمع للأديان، ورأت الجماعة ان الفكرة تتناقض مع القرآن الكريم، اولا: لان القرآن اوضح ان الدين عند الله الاسلام، ومن يبتغ غير الاسلام دينا فلن يقبل منه. وكيف يمكن لمسلم ان يقوم بالمساهمة في بناء كنيسة أو معبد يهودي، على قدم المساواة مع المسجد الذي يمثل الدين الوحيد المقبول عند الله؟. ثانيا: ان القرآن اوضح ان اهل الكتاب قد غالوا في دينهم وقاموا بتحريفه، فلا يمكن اذا بدامة ان يتم وضع دين صحيح واديان اخرى محرفة على قدم المساواة، ثالثا: كيف يمكن لدولة مسلمة ان تشارك في بناء كنيسة، وتضع في اعلاها صليبا، والقران ينفي؟، بل ويؤكد ان المسيح لم يصلب، ان امل الكتاب يتحدان في الكيد للإسلام، وانهم قاموا بفضائع في الحروب الصليبية، بل انهم ادوا دورا رئيسيا في تفتيت وحدة المسلمين واسقاط الخلافة الاسلامية(100). كما كتب المرثد العام للاخوان (كلمة الدعوة) في مجلة (الدعوة) وذكر بأن الاقباط في مصر يتمتعون بحقوق لم تتمتع بها اقلية في حجمها في اية بقعة من بقاع العالم، واتهم الاقباط بأثارة الفتنة الطائفية

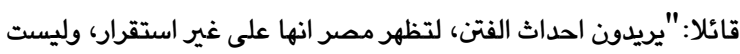
مصر هي هدفهم، انما هدفهم الحكم، ليعيثوا في الارض فسادا، كما عاث فيها فسادا آخر لهم من قبل، ولن يجدوا آذانا صاغية لها اثرها فيما يريدون، انما هي فرقعة هنا، وطرقعة هناك ولا شىء الا كما يحرك النسيم الواهن، صفحات الغدير الهاديء الرقراق"، وحذر الاقباط في نهاية كلمته ونصحهم، بالقول:"اني انصح الهائجين من الاقباط ان يرعووا قليلا، فلن ينفعه احد، حتى ولو اعتقدوا أن الدنيا كلهم معهم، والشرر أن تطاير فلن يبقى احد"، ثم نصح المسلمين بالتمسك بوطنهم، بالقول:"وأني انصح الهائجين من المسلمين أن يتبينوا مواقع اقدامهم،

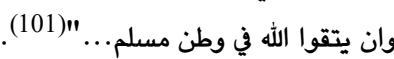
ومع ما تقدم، فقد حاول الاخوان تهدئة الاوضاع في عدد من الحالات، فعلى سبيل المثال فقد شكل فريق للمصالحة بين المسلمين والاقباط ضم كل من عمر التلمساني، مصطفى مشهور، حافظ سلامة، أحمد المحلاوي وعبدالمنعم ابو الفتوح، وتمكنت من تحقيق المصالحة بين

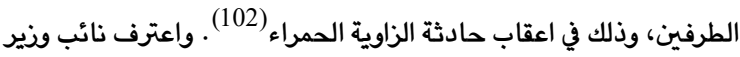
الداخلية نبوي اسماعيل بأن القيادات الدينية الاسلامية ادت واجباتها بمسؤولية، وذهبوا الى المساجد التي توجد بها التجمعات المثيرة للفوضى للتصدي للتطرف، وتخفيف حدة التوتر في الجامعات، وكان من بينهم عمر التلمساني وسليمان الربيع وعصام العريان وحلمي الجزار، كما ادت القيادات المسيحية ايضا بمسؤولياتها وعملوا لتهدئة الامور (103). حلل مرثد الاخوان اسباب الفتنة الطائفية وتداعياتها، والقى كامل المسؤولية على النظام الحاكم، واثار عدة تساؤلات بالقول:"... أين كان الحكم وحراسه طيلة السنين؟! ولماذا لم يقضوا عليها قبل ان 
طلاب المسيحيين بالجامعة أو خارجها، بل ان الجماعة الاسلامية سارت على ادب الاسلام "لهم ما لنا وعليهم ما علينا"، ورأت الجماعة بأن حدوث مشادة بين طالب مسيحي وآخر مسلم، لا ينبغي فهمها ذلك على

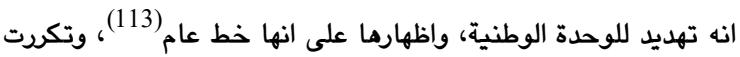
اعتداءات الجماعة على الاقباط، منها اعتداءها على الطلاب المسيحيين

المقيمين بالمدينة الجامعية بالاسكندرية في 18 اذار 1980 19 (114). وعلى اثر تفاقم العلاقات بين جماعات الاسلام السياسي والحكومة والكنيسة، انعكس ذلك سلبا على تطورات الوضع الداخلي، اذ امتدت مظاهر الفتنة الطائفية الى انحاء اخرى في مصر منها صعيد مصر، اذ حاولت الجماعة الاسلامية في جامعة اسيوط بمنع طلبة الاقباط من الاحتفال بأعياد دينية. مما دفع رئيس الوزراء الى اصدار تعليمات مباشرة الى وزير الداخلية بالتصدي لذلك بالقوة، واتاحة الفرصة للطلبة المسيحيين بالاحتفال بأعيادهم (115). وفي حادثة مشابهة قامت الجماعة بادية الاسلامية في مدينة المنيا بجمع الطلاب الاقباط في المدينة الجامعية

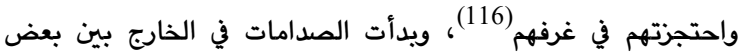
عائلات الاقباط والمسلمين في 8 نيسان 1981، فتدخلت فيها الشرطة، والقت القبض على بعض من اعضاء الجماعة الاسلامية، وقامت بحلق لحاهم، وقد استفز هذا الاجراء اسر المعتقلين، فقاموا بمحاصرة قسم بهم الشرطة المحبوس فيه ابنائهم، واضطر وزير الداخلية الى عقد صفقة مع امير عام للجماعة الاسلامية حلمي الجزار، للذهاب الى المنيا والعمل على تهدئة الامور، في مقابل الافراج عن المعتقلين، وقد توجه بالفعل الى الى المنيا، وكلف محي الدين احمد عيسى امير الجماعة بالنزول الى الاهالي

ودعوتهم المى الهدوء، ونجح في مسعاه، وافرج عن المعتقلين(117). انتهزت الجماعة الاسلامية لنشوب الخلافات الدائرة بين الحكومة والاقباط، اذ عقدت الجماعة الاسلامية في 8 نيسان 1980 مؤتمرا كبيرا في جامعة القامرة، هاجم فيها امير عام الجماعة حلمي الجزار الاقباط

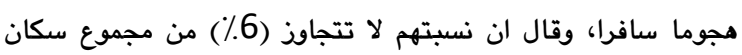
مصر، وانهم تمتعوا بمزايا لا تتمتع بها اي اقلية في العالم، وهم يتولون اعلى المناصب منها وزير الدولة للشؤون الخارجية بطرس بطرس غالي، وامين الحزب الوطني الحاكم فكري مكرم عبيد، ومحافظ سيناء فكلهم مسيحيين. قامت سلطات الامن ويعد ايام معدودة من بألقاء القبض على شباب الجماعة الاسلامية في المنيا بعد وقوع حوادث العنف الطائفي، وعلى رأسهم محي الدين احمد عيسى امير الجماعة الاسلامية في جامعة المنيا، وفي 18 نيسان 1980 عقدت الجماعة الاسلامية مؤتمرا في مسجد صلاح الدين بالقامرة، اتهم عصام العريان فيها الاقباط بانهم يزعمون ان مصر بلدهم، وان المسلمين مستعمرون مثل اليهود في باني فلسطين، وهدد قائلا: بأن النصارى المتطرفين لن يضروا احدا غير ابناء ملتهم. ولم يقتصر الامر على هذا بل اصدرت الجماعة الاسلامية بيانا خطيرا بعنوان (الابعاد الحقيقة للفتنة الطائفية)، اتهمت فيه الاقباط باثارة الفتنة الطائفية، واكد ان الاسلام حرمم من عبودية
سعوا الى خلق دولة دينية طائفية، وهي بحد ذاتها مؤامرة ضد (107) مصول) (ل)

\section{0. موقف الجماعات والتنظيمات الاسلامية الاخرى من \\ الاقباط}

كان موقف الجماعة الاسلامية(108) متشددا ضد الاقباط، سيما بعد ازدياد نفوذها في اواخر السبعينات من القرن العشرين، اذ بدأت الجماعة الاسلامية بالظهور مع انحسار دور التيار اليساري والناصري داخل الجامعات، اصبح الاقباط يمثلون في نظر الجماعة العقبة الوحيدة في صبغ المجتمع المصري بالصبغة الاسلامية، ونقلت الجماعة الاسلامية عداءها من التيارين اليساري والناصري الى الاقباط، واستخدمت نفس اساليب العنف معهم، الامر الذي دفع الاقباط الى تسليح انفسهم لمواجهة اي عنف يقع عليهم، ويذلك تحولت الجامعات من دور للدراسة والعلم الى دود للمصادمات الطائفية(109). عموما، كانت الجماعة الاسلامية اكثر تشددا تجاه الاقباط، وكان منهجهم الفكري وموقفهم منهم نابعا من مواقف دينية متشددة تجاه الاديان الاخرى. وكانت الجماعة الاسلامية تتصرف من منطلق ان الورقة القبطية تشكل ضغطا على الحكومة المصرية، وكانت الاعتداءات المسلحة على الاقباط من جانب الجماعة الاسلامية، تنطلق من محاولة الضغط على الحكومة عن طريق الضغط على الاقباط والحاق الاذى اهى

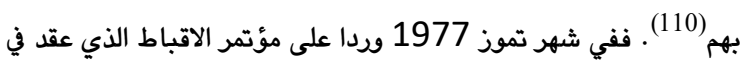
كانون الثاني 1977، عقد مؤتمر الهيئات والجماعة الاسلامية تحت وتهردي رعاية شيخ الجامع الازمر عبدالحليم محمود، واصدر المؤتمر بيانا ختاميا اوصى فيه على ان كل تشريع أو حكم خالف ما جاء به الاسلام باطل، ودعا الى تطبيق الشريعة الاسلامية، وليس لاحد حق في ابداء رأيه في وجوب ذلك، وانهم لا يقبلوا مشورة بالتمهل أو التدرج أو التأجيل، وان التسويف في اقرار القوانين الاسلامية "معصية لله ورسوله" وأه وأى المؤتمر ان ما صرح به الرئيس السادات عن عزمه تطهير اجهزة الدولة من الملحدين خطوة ايجابية، وناشده الى اصدار اوامر بتطهير وسائل الاعلام كذلك، واقر ان تكون اللجنة التنفيذية للمؤتمر في حالة انعقاد مستمر، لمتابعة الجهود التي تعبر عن اجماع الامة على ضرورة تطبيق

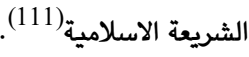
اتسم موقف الجماعة الاسلامية بالازدواجية، اذ بعد ان ازداد نفوذها، دخلت في صدام مع مجموعات قبطية في اماكن مختلفة وخاصة في الصعيد والاسكندرية، وفي الوقت نفسه الذي بدأت هذه الجماعات في

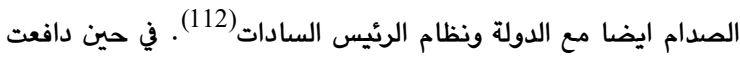
الجماعة الاسلامية عن نفسها في احد البيانات في صيف 1979 على انها ترفض كل اشكال العنف والعمل السري، وتتصدى للأفكار المتطرفة أو المنحرفة، ونفت الجماعة الاسلامية اتخاذ مواقف سلبية تجاه المسيحيين، واكدت انها حرص على الوحدة الوطنية، وعدم مس شعود 
حاربوا الاسلام واحل لهم قتالهم واخذ اموالهم (126). وساهم عامل آخر في معاداة المسيحية حسب وجهة نظرهم وهو ان التبشير المسيحي يعد

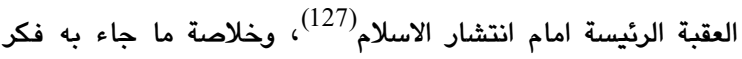
تنظيم الجهاد انه رفض فكرة المواطنة في العلاقة مع غير المسلمين، ويرى انهم اهل ذمة، متبنيا الموقف التقليدي للفقه الاسلامي منهم (128). عمد مجلس شورى تنظيم الجهاد على تبني خطة تمويل التنظيم عن

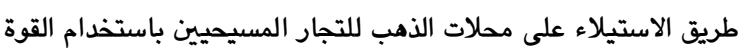
والعنف، اذ بدأ بتطبيق الخطة في حزيران 1981 بمهاجمة عدد من محلاتهم في مدينة نجد حمادي في محافظة قنا، وهم ملثمين حاملين

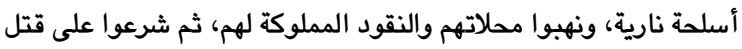
عدد من اصحاب محلاتهم منهم كما على سبيل المثال لا الحصر: فوزي مسعود اسكاروس، جرجيس فوزي مسعود، ماهر فوزي مسعود، طريف بشير شنودة، وشهدت حوادث مماثلة في دائرة قسم الاول بشبرا الخيمة

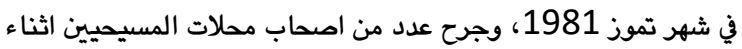
دفاعهم عن انفسهم وممتلكاتهم، وياعوا بعض منها مما نهبوا من الذهب عن طريق نوجات اعضاء التنظيم، وخزن قسم اخر منها (129). دخلت جماعة الجهاد في خط المواجهة مع الاقباط بالقيام في سلسلة من العمليات، منها احراق محل لبيع الخمر لاحد الاقباط بمنطقة مصر القديمة في 2 نيسان 1980، وماجمت في الاول من اب 1981 على لي محل للذهب تملكه امرأة مسيحية بمنطقة شبرا بالقاهرة، وقد قتل فيها

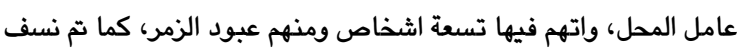
كنيسة مصر بشبرا ليلة 3 اب 1981، وقد حوكم على اساسها الرائد

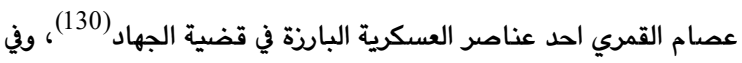
المحصلة كانت جماعات العنف من امم مصادر تغذية الشعور بالطائفية والاحتقان الطائفي، سواء بأفكارها المتطرفة في التطرق الى الاقباط في ادبياتها وافكارها ومنشوراتها، مما اثر سلبا على قطاعات من المجتمع

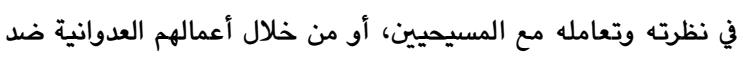
الاقباط واستحلال اموالهم لتمويل انشطتهم، أو استحلال دمائهم وقتل عدد منهم سواء في أحداث عنف مباشر أو اعتداء على كنائس (131)، وعلى الرغم مما قام التنظيم بأعمال لاثارة الفتنة الطائفية، الا ان مفتي التنظيم عمر عبدالرحمن عد الفتنة الطائفية من اختلاق النظام، لإظهار نفسها كمدافع عن الاقباط في مصر وحمايتهم (132).

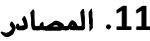

1. جمال بدوي، الفتنة الطائفية في مصر جذورها واسبابها دراسة تاريخية

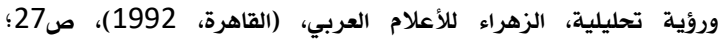

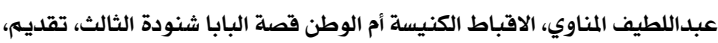

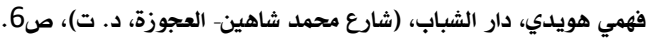
2. أبو سيف يوسف، الاقباط والقومية العربية دراسة استطلاعية، مركز

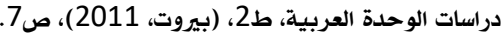

الرومان، ورد اليهم كرامتهم، واذهم ينعمون كأقلية بما لا تنعم به الاقليات المسلمة التي يحكمها "النصارى"، وطالب بالقضاء على دكتاتورية الاقلية، واختتم البيان بالقول بضرورة أن يقابل الاقباط

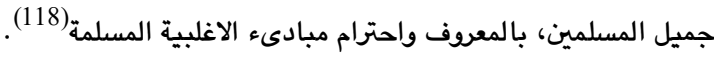
اتسم موقف تنظيم الفنية العسكرية(119) بالتشدد تجاه الاقباط، رغم ان صالح سرية لم يذكر في كتابه (رسالة الايمان) اسم الاقباط الا انه هاجم المسيحية بشكل عام، ومادام انه كفر المسلمين فكيف الحال بالنسبة لغير المسلمين؟، وذكر صالح سرية ان الله انزل عددا من الكتب على انبيائه منها التوراة والانجيل والزبود وعدد من الصحف، وعدها من الكتب المحرفة، وان القرآن نسخ كل الكتب السابقة، وان محمد هو خاتم الانبياء فرض على امته الاقتداء بهديهم ونسخت شريعته جميع شرائع

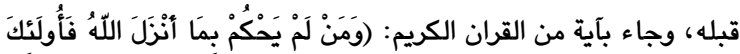

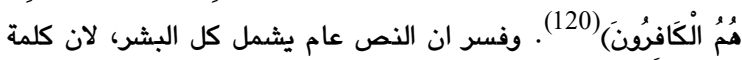
(من) بعموم اللفظ، على ان القصد لا يحتاج لكل هذا الجهد في الاثبات لهذه البديهية، واكد ان الاسلام ليس دين عبادة بالمفهوم المسيحي، انما هو دين له منهجه وشرعه، وان المناهج والعقائد اذا ثبتت انها مطابقة للإسلام ليس بكفر، اما اذا كانت مخالفة فالكفر فيها واضح، اي انه كفر المسيحيين ضمنيا ومنهم الاقباط دون الاشارة الى اسمهم صراحة(121)، واكد على ضرورة الزام المسيحيين والمسيحيات بارتداء زي يعرفون به في الدولة الاسلامية(122). كما اتذذ تنظيم الجهاد(123) مواقف متشددة من الاقباط مصحوية بالعنف، ورأى التنظيم ان العلاقة بين المسلمين والاقباط، هي علاقة المواجهة المباشرة، فالأقباط بالنسبة لهم هم خصوم دينيين وسياسيين، يتعين عليهم قبول وضعية امل الذمة، من حيث دفع الجزية صاغرين، والقبول في الدخول للإسلام، وفي حالة قيامهم بمقاومة الاسلام

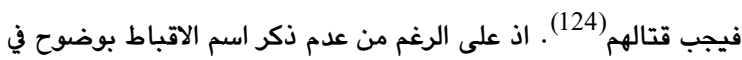
كتيب (الفريضة الغائبة) لمحمد عبدالسلام فرج، الا انه لم يتم استثناؤهم من باقي الطوائف التي دعى الى القتال معها، واستند حكمه الى نص اقتبسه من ابن تيمية بجهاد الكفار الى ان يسلموا ويؤدوا الجزية عن يد وهم صاغرون. واكد محمد عبدالسلام فرج بضرورة اعلان الجهاد

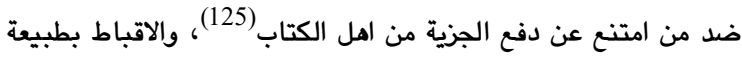
الحال هم طائفة من اهل الكتاب. بينما استندت النيابة العامة في تحقيقاتها، انه بناءا على عرض قدمه اعضاء مجلس شورى التنظيم حول موقفهم من المسيحيين، فأكد عمر عبدالرحمن: ان المسيحيين هم ثلاثة اقسام، مسيحي اعتدى على مسلم وقتله يكون دمه حلال. ومسيحي يساعد الكنيسة ويشترى لها السلاح لمحارية المسلمين يكون ماله مباح. ومسيحي لا يعتدى على مسلم ولا يشتري سلاحا لمحاريته

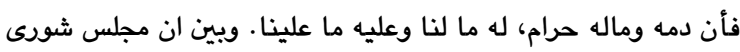
التنظيم عرض عليه موضوع حول سرقة اموال بعض المسيحيين في الفيوم، فأفتى عمر عبدالرحمن بجواز ذلك شرعا، لان "النصارى" 
20. كمال حبيب (الدكتور)، تحولات الحركة الاسلامية والاستراتيجية

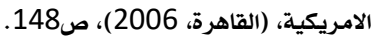

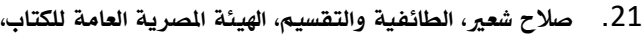

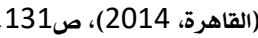
22. نظير جيد روفائيل، ولد سنة 131 1923، بابا الاسكندرية وبطريرك

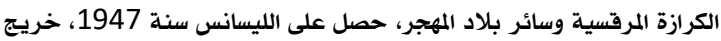

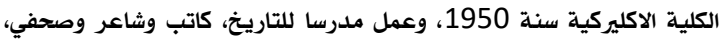

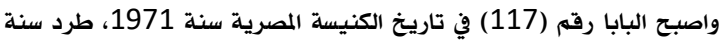
1981 من منصبه، وأعيد تعينه في 3 كانون الثاني 1985 بابا الاسكندرية وبطريرك الكرازة المرقسية بقرار رئيس الجمهورية، توفي في 17 اذار 2012.

للمزيد من التفاصيل ينظر: الصصدر نفسه، ص125 وما بعدها.

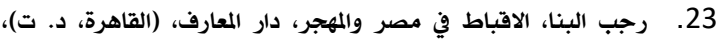
ص46؛ صلاح شعير، المصدر السابق، ص126.

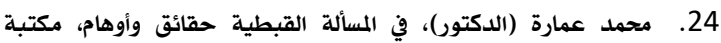
الشروق، (القاهرة، 2001)، ص55 وبعدها؛ كامل عبدالفتاح احمد بحيري (الدكتور)، التطور الفكري لدى جماعات العنف الدينية في مصر الاسلامية ولاملية

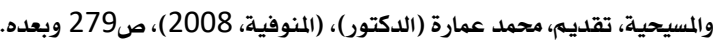
25. أبو العلا ماضي، المصدر السابق، ص47 وما بعدها.

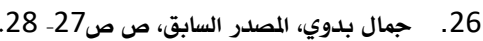

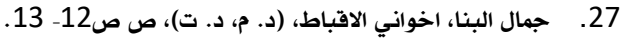

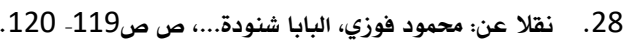

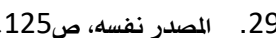

30. مقتبس من مؤلفه: المصدر السابق، ص ص60. 31. فؤاد زكريا (الدكتور)، الحقيقة والوهم في الحركة الاسلامية المعاصرة،

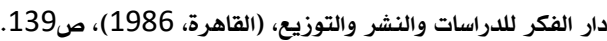

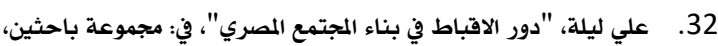

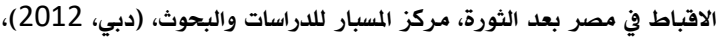

33. نبيل عبدالفتاح، المصدر السابق، ص342.

34. هالة مصطفى (الدكتورة)، الدولة والحركات الاسلامية المعاصرة بين المهادنة والمواجهة في عهدي السادات ومبارك، مركز المحروسة للنشر والخدمات الصحفية، (المعادي-القاهرة، 1996)، ص272.

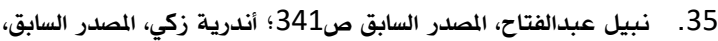
ص198. - n

36. غالي شكري، المصدر السابق، ص21. 37. نقلا عن: محمود فوزي، النبوي اسماعيل وجذور منصة السادات، دار

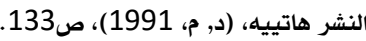

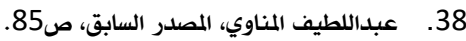
39. اكرام لمعي (الدكتور)، المسيحيون بين الوطن والمقدس الدور والمصير،

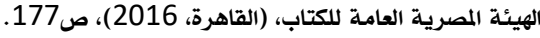

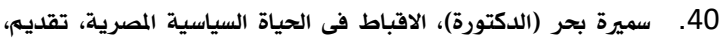

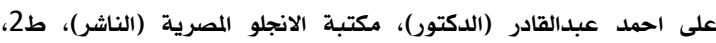

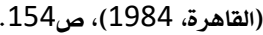

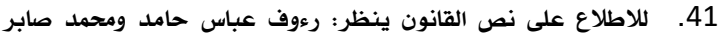

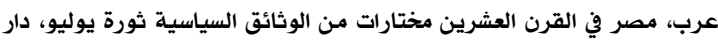

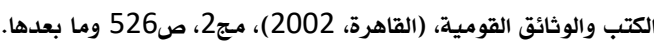
42. للمزيد من التفاصيل ينظر: غالي شكري، الصصدر السابق، ص217
3. اندرية زكي (الدكتور)، الاسلام السياسي والمواطنة والاقليات مستقبل المسيحيين العرب في الشرق الاوسط، مكتبة الشؤون الدولية، (القاهرة، 2006)،

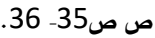

4. عزمي بشارة، هل من مسألة قبطية في مصر، المركز العربي للأبحاث

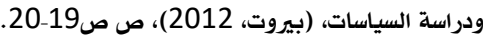

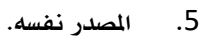

6. نبيل عبدالفتاح، النص والرصاص الاسلام السياسي والاقباط وأزمات

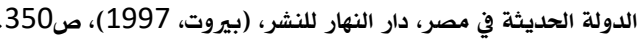

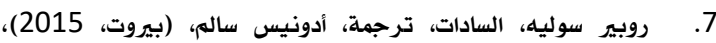

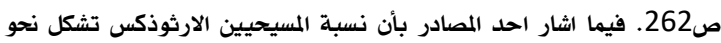

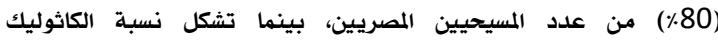
والبروتستانت نسبة (20٪). ينظر: أبو العلا ماضي، المسألة القبطية والشريعة والصحوة الاسلامية، تقديم، طارق البشري، سفير الدولية للنشر، (القاهرة، 2007)، صوالصوة الاسلامية.

8. للمزيد من التفاصيل ينظر: أبو سيف يوسف، المصدر السابق، ص17

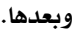
9. نقلا عن: محمود فوزي، البابا شنودة والمعارضة في الكنيسة، دار نشر

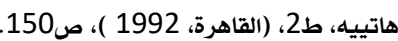
10. (6,74). للمزيد من التفاصيل ينظر: جمال حمدان، شخصية مصر دراسة في

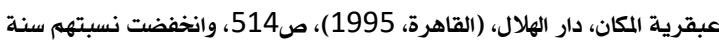

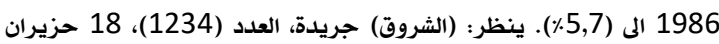

.2012

11. (الشروق) جريدة، العدد (1234)، 18 حزيران 2012. 12. سامية عياد عطا، الشاركة السياسية للاقباط، تقديه، ثروت العردئ، اسحق،

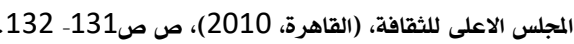
13. المصدر نفسه، ص136. 14. للمزيد من التفاصيل ينظر: نبيل عبدالفتاح، المصدر السابق، ص115 صلا13

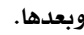
15. ولد سنة 1910، والتحق بالازهر حيث حصل على الشهادة العالمية سنة 1932، سافر الى فرنسا ودرس علم النفس والاجتماع وتاريخ الاديان في جامعة

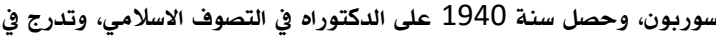

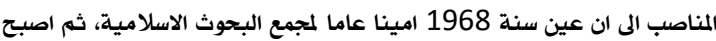

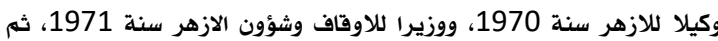
اصبح سنة 1973 شيخا للازهر، توفي في 19 وتشرين للاوف وشؤون الاول 1978. للمزيد من التفاصيل ينظر: (الاهرام) جريدة، العدد (33549)، 18 تشرين الاول .1978

16. المصدر نفسه، ص124.

17. سكوت هيبارد، السياسة الدينية والدول العلمانية مصر والهند والولايات المتحدة الامريكية، ترجمة، الامير سامح كريم، (عالم المعرفة) سلسلة كتب ثقافية شهرية يصدرها المجلس الوطني للثقافة والفنون والاداب، العدد (413)،

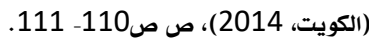
18. محمد ابراهيم المرشدي، عروبة مصر وأقباطها على طريق مشروع حضاري قومي، تقديم، محمد عمارة (الدكتور)، دار الشرق الاوسط للنشر،

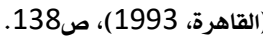
19. غالي شكري (الدكتور)، الاقباط في وطن متغير، دار الشروق، (القاهرة،

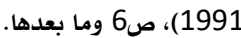


69. عبداللطيف المناوي، المصدر السابق، ص ص236- 237.

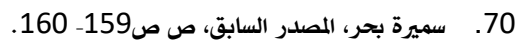

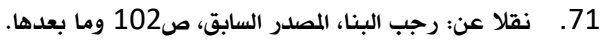

72.

73. عبداللطيف المناوي، الصدر السابق، ص246.

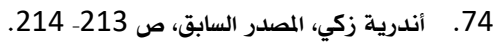

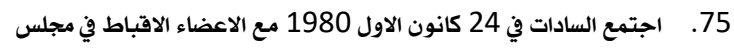

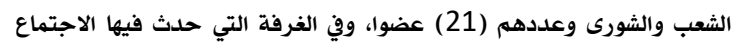

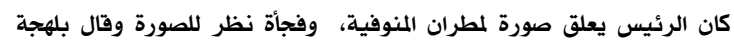

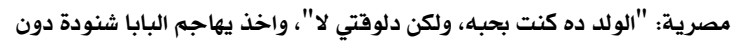

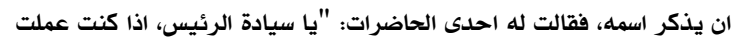

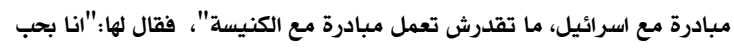

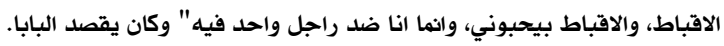

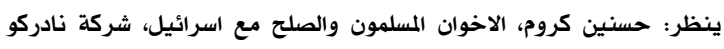

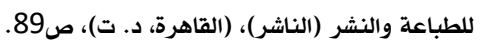

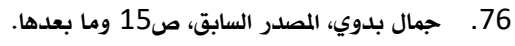

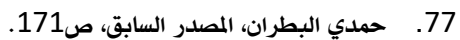

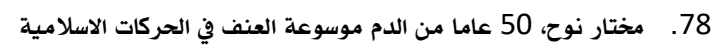

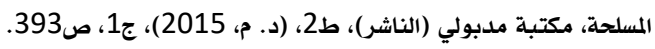

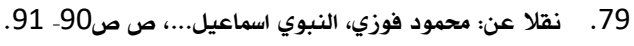

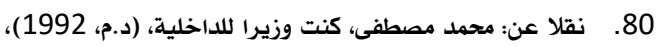

ص20.

81. ميلاد حنا،" الفتنة الطائفية فى عهد السادات غرست البذرة الأولى فى

مصر"، مقال متاح على الموقع الالكتروني:

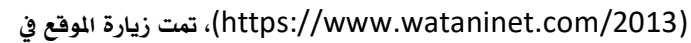
الساعة P.M 8 P. يوم 2019/1/20.

82. عمدي البطران، المصدر السابق، ص173.

83. راغب السرجاني (الدكتور)، الفتنة الطائفية الجذور الواقع المستقبل،

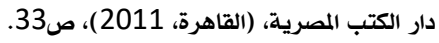

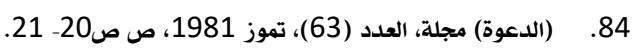

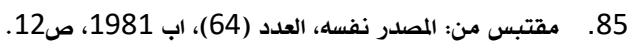

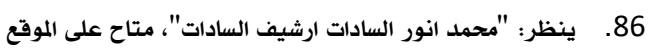

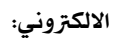

(http://sadat.bibalex.org/Historic Documents/Histori c Docs All.aspx?TabName=Speech\&page=215\#Galler

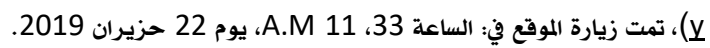
87.

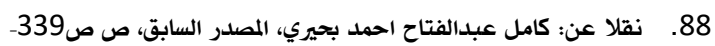
.340

89. هشام مبارك، الارهابيون قادمون دراسة مقارنة بين موقف الاخوان

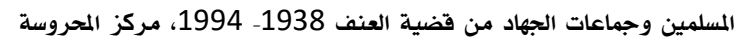

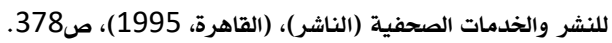

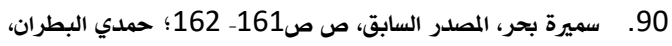

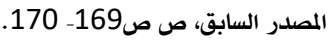
91. أندرية زكي، المصدر السابق، ص200.

92. و وهم الانبا (مكسيموس أسقف القليوبية، صموئيل أسقف الخدمات العامة وكنائس المهجر، أغريغوريوس أسقف البحث العلمي والدراسات القبطية العليا

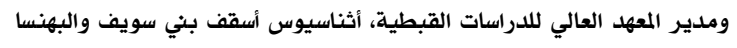

43. عبداللطيف المناوي، المصدر السابق، ص ص147ـ 148؛ ديفيد هرست

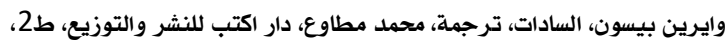

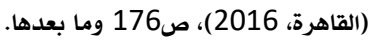

44. . كمال حبيب، المصدر السابق، ص148.

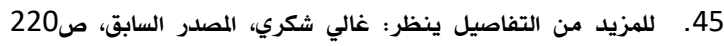

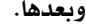

46. موسى صبري، السادات الحقيقة والاسطورة، المكتب الصرري الحديث

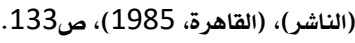

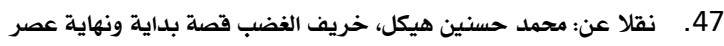

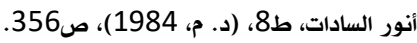

48. اندرية زكي، المصدر السابق، ص310.

49. محمد عمارة (الدكتور)، الفتنة الطائفية متى وكيف ولماذا؟، مكتبة المكابة

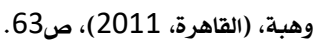

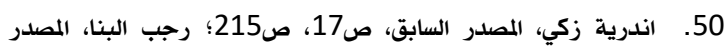

السابق، ص99. - (50.

51

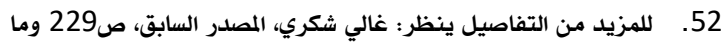

53. للمزيد من التفاصيل ينظر: المصدر نفسه، ص233 وما2 وما بعدها.

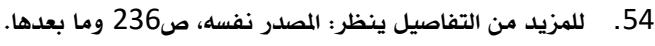

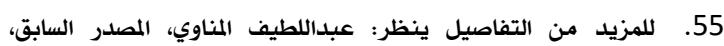

ص149 وبعدها.

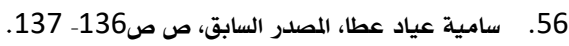

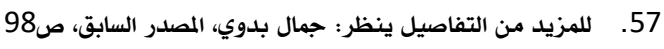

وبعدها؛ حمدي البطران، الملف القبطي، دار الثقافة الجديدة (الناشر)،

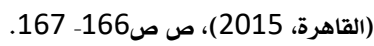

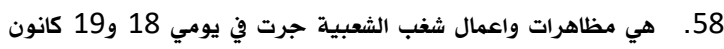

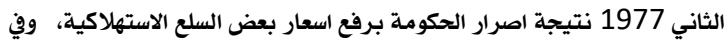
نهاية الامر أجبرت الحكومة الصرية للعدول عن فراراتها. للمزيد من التفاصيل

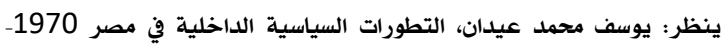
1980 دراسة تاريخية، رسالة ماجستير قدمت الى مجلس كلية التربية، جامعة

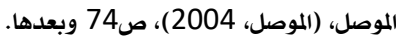

59. عبداللطيف المناوي، المصدر السابق، ص ص200، ص227 صـ 228.

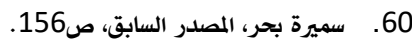

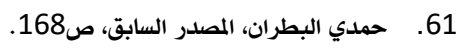

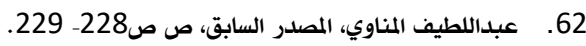

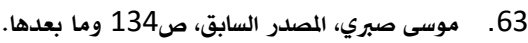

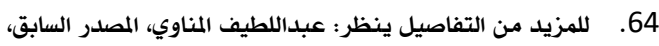

ص266 ص وبعدها.

65. محمود فوزي، حكام مصر السادات، مركز الراية للنشر والاعلام،

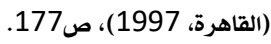

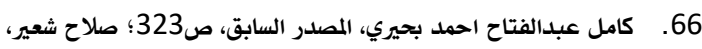

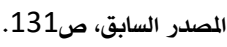

67. للمزيد من التفاصيل ينظر: رجب البنا، المصدر السابق، ص241

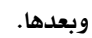

68. سامية عياد عطا، المصدر السابق، ص136 وما بعدها؛ غالي شكري،

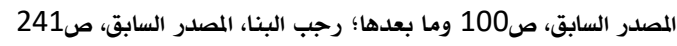

وبعدها. 
112. أبو العلا ماضي، المصدر السابق، ص ص48ـ 49.

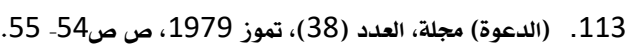

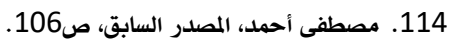

115. موسى صبري، المصدر السابق، ص1163.

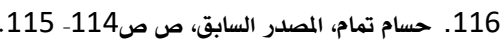

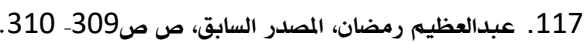

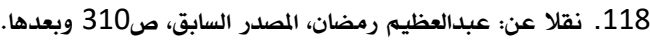

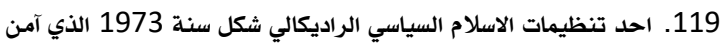

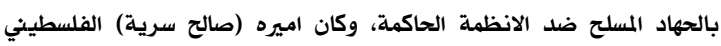

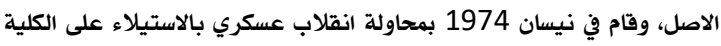

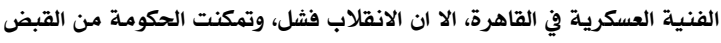

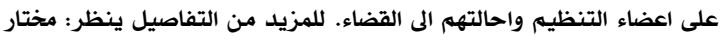

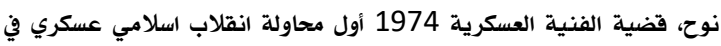
القرن العشرين، تحرير، محمد علي أبو هميلة، مركز المحروسة للنشر والخدمات

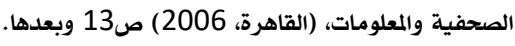
120. القرآن الكريه، سورة (المائدة)، الاية (44).

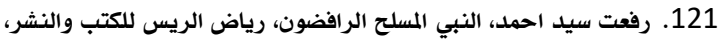

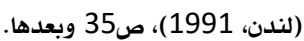

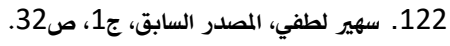

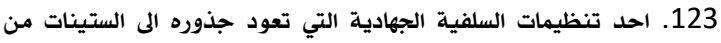

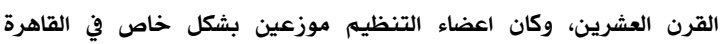
والاسكندرية، وفي سنة 1979 شكل تحالف من مجموعات الحلقات الجهادية تحت اسم (تنظيم الجهاد)، واصبح محمد عبدالسلام فرج امير التنظيم، ومن

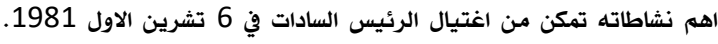
للمزيد من التفاصيل ينظر: محمد مورو (الدكتور)، تنظيم الجهاد أفكارهـ

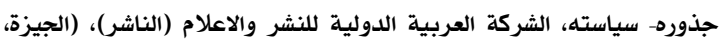

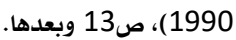

124. جمال شاكر البدري (الدكتور)، السيف الاخضر الاصولية الاسلامية

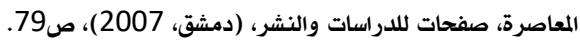

125. ينظر مؤلفه، الفريضة الغائبة، ص ص6ــــ 7.

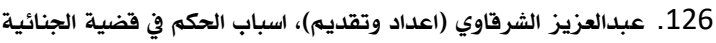

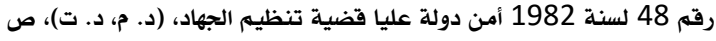

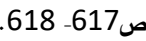

127. جيلز كيبل، النبي والفرعون، ترجمة، احمد خضير، مكتبة مدبولي، المطبعة الفنية، (د. م، 1288 1988)، صيلز البي والفرعون ترجمة.

128. كمال السعيد حبيب (الدكتور): "جماعة الجهاد المسار والافكار

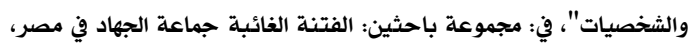

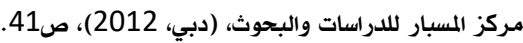

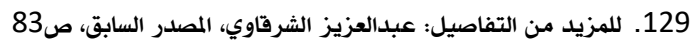

وبعدها.

130. رفعت سيد احمد، الاسلامبولي رؤية جديدة لتنظيم الجهاد، دار

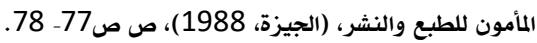

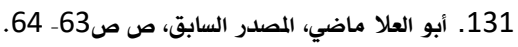

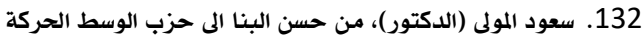

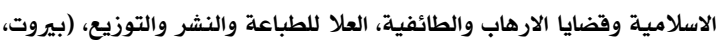

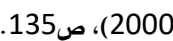

ويؤانس أسقف الغربية وسكرتير المجمع المقد). للاطلاع على نص القرار

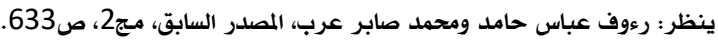

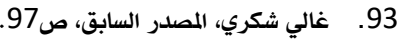

94. عمر التلمساني"الدين والسياسة والاحزاب"، (الدعوة) مجلة، العدد المدابل

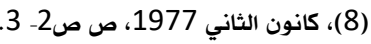

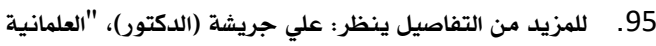

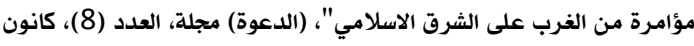

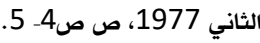

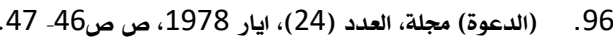

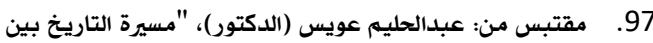

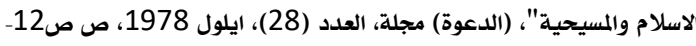

98. مصطفى محمد الطحان، الاخوان المسلمون في مصر 1928ــ 2005، 2005،

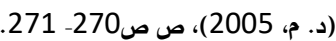
99. السيد يسين (التحرير)، التقرير الاستراتيجي العربي 1987، صلإل، مركز

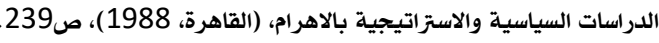

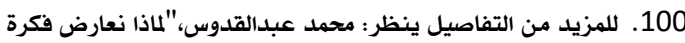

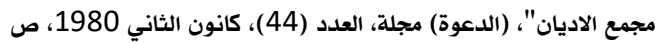

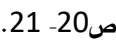

101. مقتبس من: عمر التلمساني، "للدعوة كلمة: حول الوحدة الوطنية"،

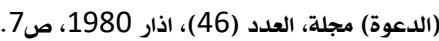
102. حسام تمام (تحرير)، عبدالمنعم ابو الفتوح شاهد على تاريخ العار الحركة

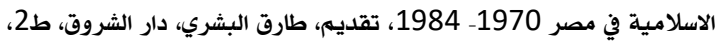

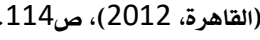

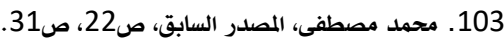

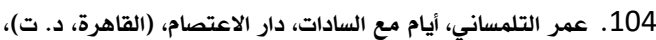
ص98. 105. للاطلاع على نص النداء ينظر: (الدعوة) مجلة، العدد (63)، تموز

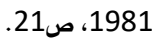

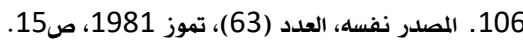

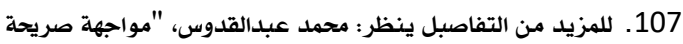

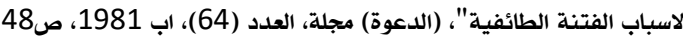

وبعدها.

108. يعود نشأت الجماعة الاسلامية في مصر كجزء من الحركة الطلابية في الجامعات الى السبعينات من القرن العشرين، وتعددت اسماء الجماعات مثل (الجماعة الدينية، الجماعة الاسلامية، الجمعية الدينية ولجنة التوعية

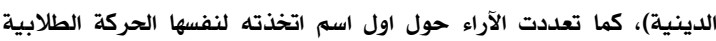

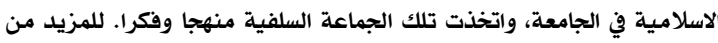

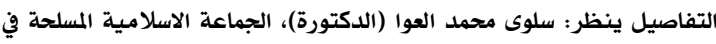

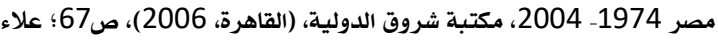
بكر (الدكتور)، الصحوة الاسلامية في السبعينيات، دار الخلفاء الراشدين،

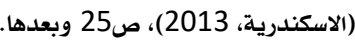

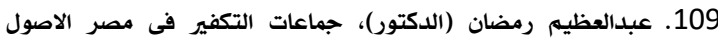

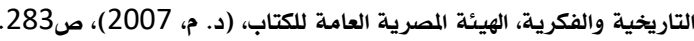

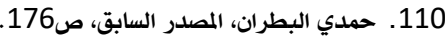
111. حمدي البطران، المصدر السابق، ص168. 


\title{
Groups and Organization of Political Islam during the president Mohammad Anwar Al- Sadat 28 September
} 1970- 6 October 1981

(A Historical and Political Study)

\begin{abstract}
Abstruct:
The interpretations differed in analyzing the significance of sectarian sedition events in Egypt's modern history. However, the ruling authority bears a big amount of responsibility about stressing the atmospheres and provoking sectarian sedition, because the president Sadat resorted to enter into political alliances and combine the power of the church with political Islam.He played on all ropes with all sides. At the time that the Coptic Church noticed that the regime allied whit the political Islam in order to achieve some of its political goals which raised their deep concern about the continuation of that policy and the effects of discrimination against them. In other side political Islam groups had seen that the regime aligned whit the church especially procrastination in the application of Islamic law, while the regime had seen that the both sides the church and the political Islam are elements of threatening the security and political destabilization. The authority did not hesitate in exercising that policy to contain the political conflicts with sound logic and finding exchange trust between them, which has lost its political correctness largely and the inability of the authority to maintain a balance between the two sides with political skillful and wisdom. This ultimately mode both sides rivals to the government as well as ideological conflict between the both sides, which led to escalating tensions and consequently violent clashes.
\end{abstract}

\section{Keywords:}

